\title{
Cylinder Test Specification
}
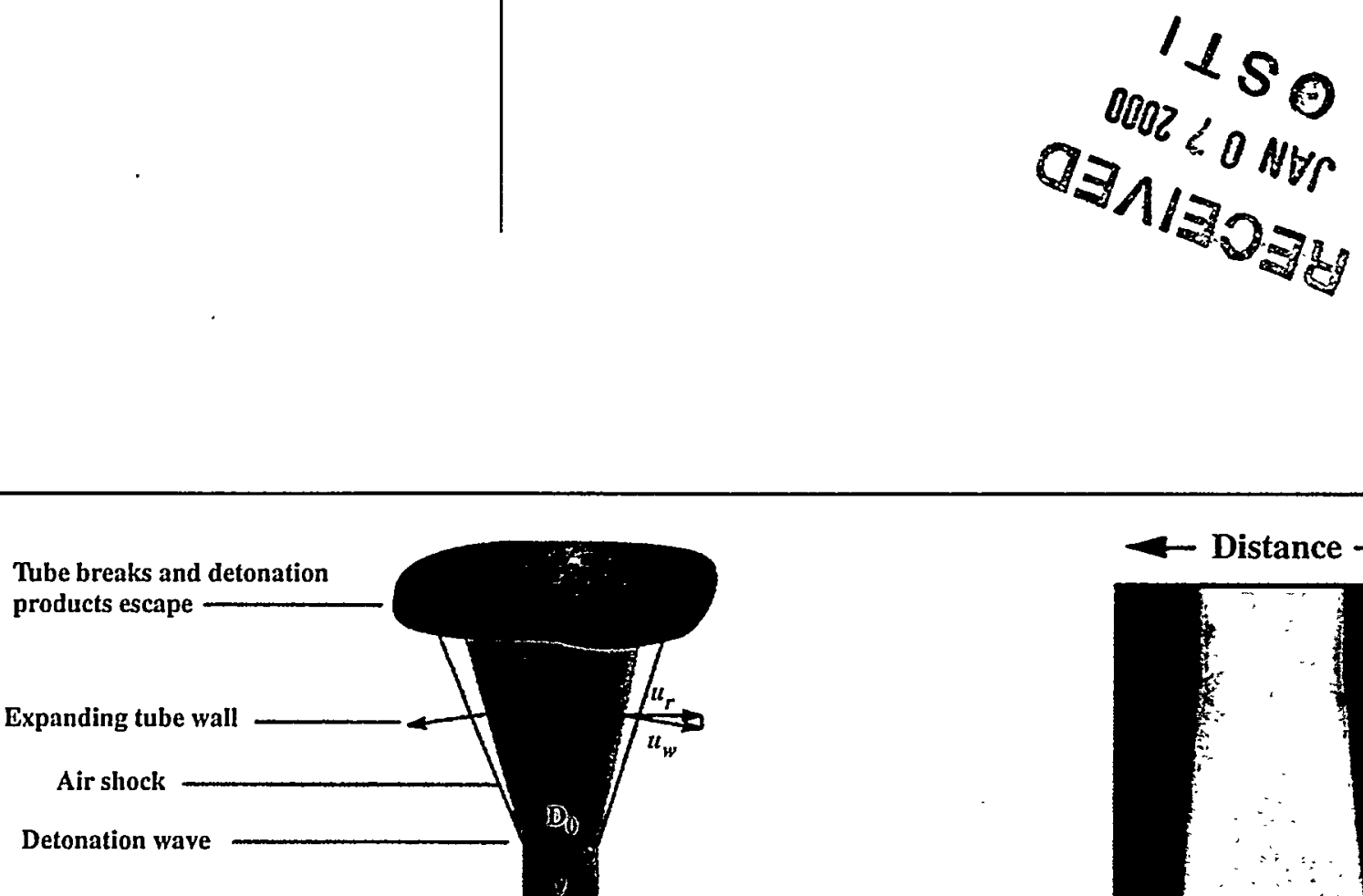

Pin wires
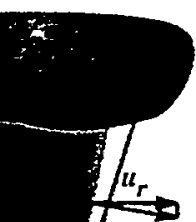

$\underset{u_{w}}{\longrightarrow}$

Bi)
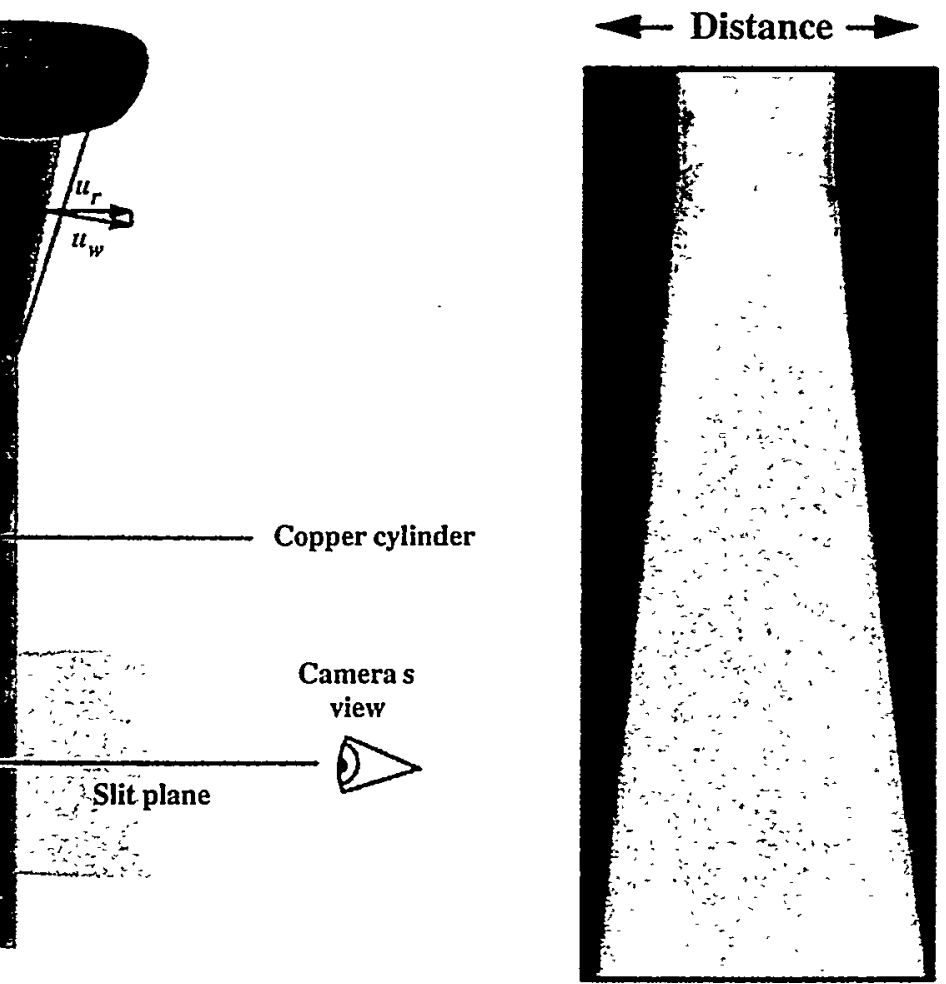

Tube is electrical ground

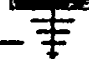

Copper cylinder

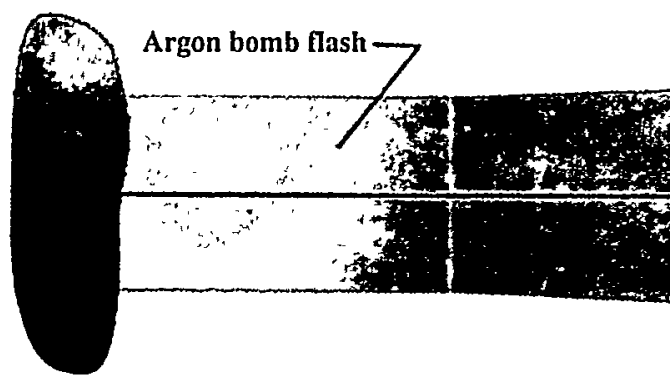

Schematic

Streak Record

\section{Los Alamos}

Los Alamos National Laboratory is operated by the University of California for the United States Department of Energy under contract W-7405-ENG-36. 
Cover photo: Cylinder test schematic and streak record (provided by Larry Hill).

An Affirmative Action/Equal Opportunity Employer

This report was prepared as an account of work sponsored by an agency of the United Siates Government. Neither The Regents of the University of Californin, the LInited States Government nor any agency thereof, nor any of their employees, makes any zarranty, express or implied, or assumes any legal liability or responsibility for the accuracy, completeness, or usefulness of any information, apparatus, product, or process disclosed, or represents that its use would not infringe privately owned rights. Reference herein to any specific commercial product, process, or service by Irade name, trademark, manufacturer, or otherwise, does not necessarily constitute or imply its endorsement, recommendation, or favoring by The Regents of the University of California, the United States Government, or any agency thereof. The viezus and opinions of authors expressed herein do not necessarily state or reflect those of The Regents of the University of California, the United States Government, or any agency thereof. Los Alamos National Laboratory strongly supports academic freedom and a researcher's right to publish; as an institution, however, the Laboratory does not endorse the viewopoint of a publication or guarantee its technical correctness. 


\section{DISCLAIMER}

\section{Portions of this document may be illegible in electronic image products. Images are produced from the best available original document.}


Cylinder Test Specification

Richard Catanach

Larry Hill

Herbert Harry

Ernest Aragon

Don Murk 


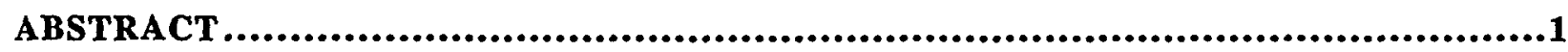

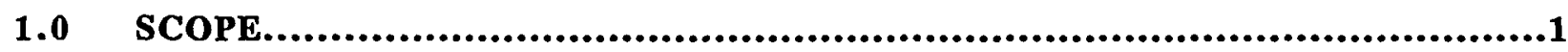

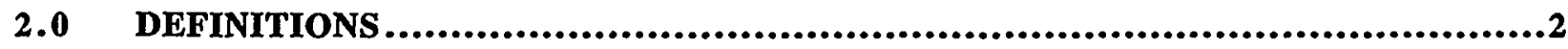

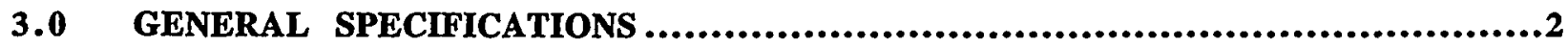

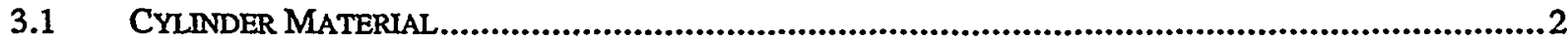

3.2 PREMACHINED (INITIAL) CYLINDER DIMENSIONS.........................................................2

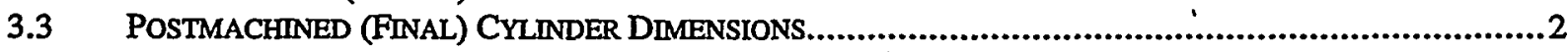

3.4 CYLINDER HEAT TREATMENT.................................................................................3

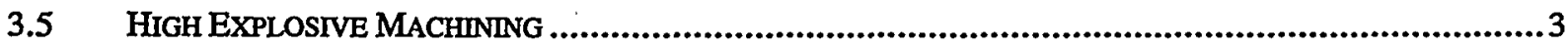

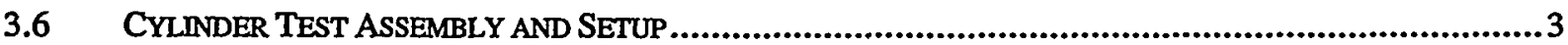

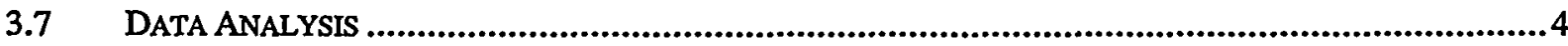

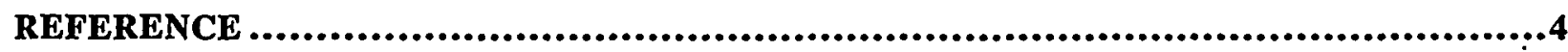

\section{APPENDICES}

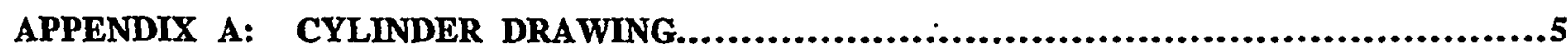

APPENDIX B: CYLINDER MACHINING PROCEDURE.....................................6

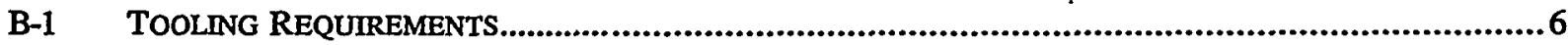

B-2 MACHINING PROCEDURES ................................................................................................

APPENDIX C: CYLINDER HEAT TREAT AND ETCHING PROCEDURE......................7

C-1 ANNEALING PROCESS.....................................................................................................

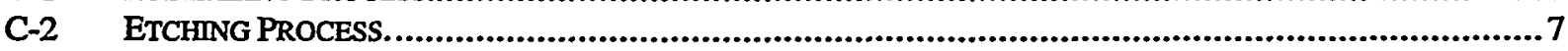

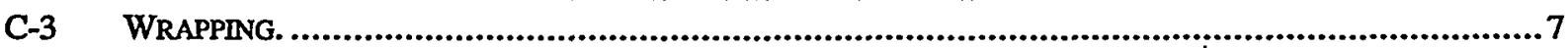

APPENDIX D: CYLINDER TEST ASSEMBLY PROCEDURE................................8

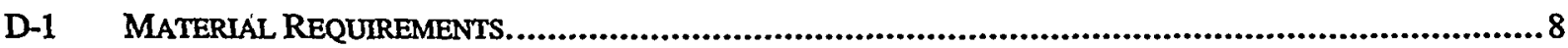

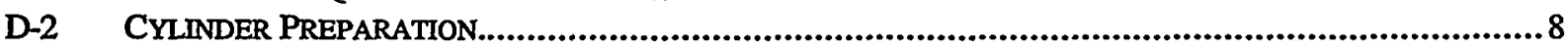

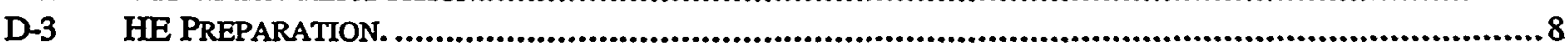

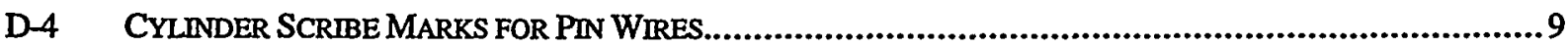

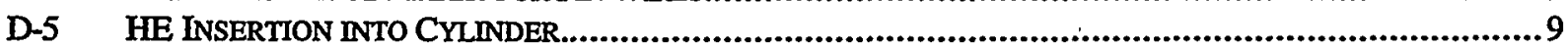

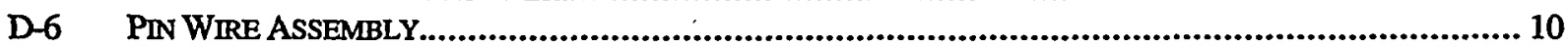

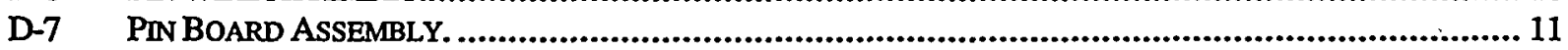

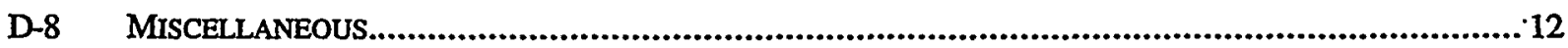

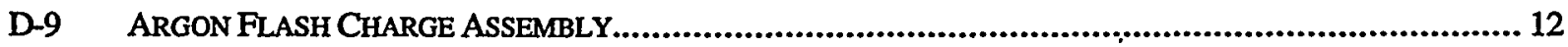

APPENDIX E: MATHEMATICA ${ }^{\star}$ ANALYSIS OF CYLINDER TEST \#15-2861...............13

E-1 NOTEBOOK AND ANALYSIS INFORMATION.............................................................................. 13

E-2 SHOT INFORMATION............................................................................................................. 14

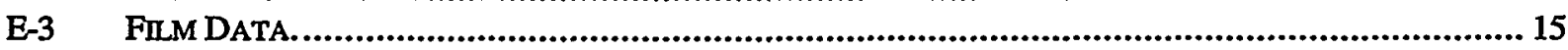

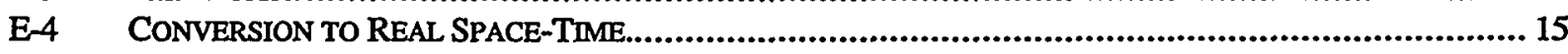

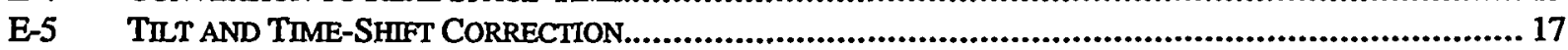

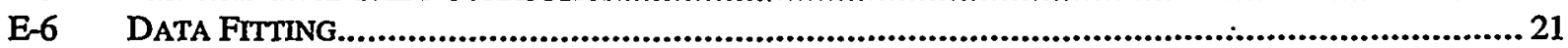

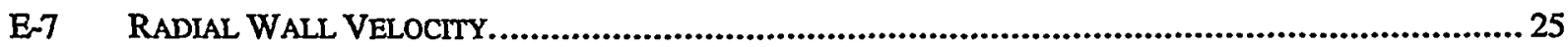

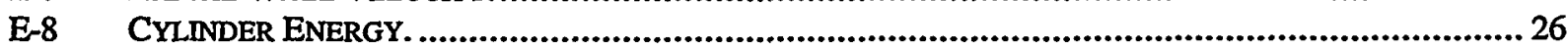

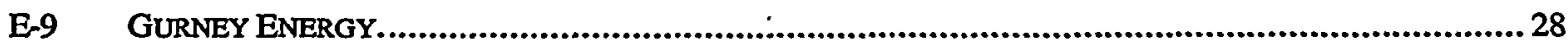

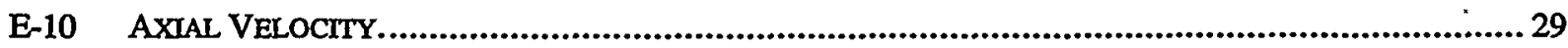




\title{
Cylinder Test Specification
}

\author{
by \\ Richard Catanach, Larry Hill, Herbert Harry, Ernest Aragon, and Don Murk
}

\begin{abstract}
The purpose of the cylinder test is two-fold: (1) to characterize the metal-pushing ability of an explosive relative to that of other explosives as evaluated by the $E_{19}$ cylinder energy and the $G_{19}$ Gurney energy and (2) to help establish the explosive product equation-of-state (historically, the Jones-Wilkins-Lee (JWL) equation). This specification details the material requirements and procedures necessary to assemble and fire a typical Los Alamos National Laboratory (LANL) cylinder test. Strict adherence to the cylinder. material properties, machining tolerances, material heat-treatment and etching processes, and high explosive machining tolerances is essential for test-to-test consistency and to maximize radial wall expansions. Assembly and setup of the cylinder test require precise attention to detail, especially when placing intricate pin wires on the cylinder wall. The cylinder test is typically fired outdoors and at ambient temperature.
\end{abstract}

\subsection{SCOPE}

The typical Los Alamos National Laboratory (LANL) cylinder test consists of a precisionmachined, annealed, oxygen-free high-conductivity (OFHC) copper cylinder filled with precision-machined cylindrical segments of solid high explosive (HE). The HE is detonated at one end, which causes the cylinder to expand in a funnel shape. The radial expansion of the cylinder wall is observed at an axial location where the detonation velocity is constant with a rotating mirror streak camera backlit by an argon-bomb flash. The axial detonation velocity is measured using fine electrical pin wires mounted to the side of the cylinder. The experiment is shown schematically in Figure 1, along with a reproduction of an actual streak record.

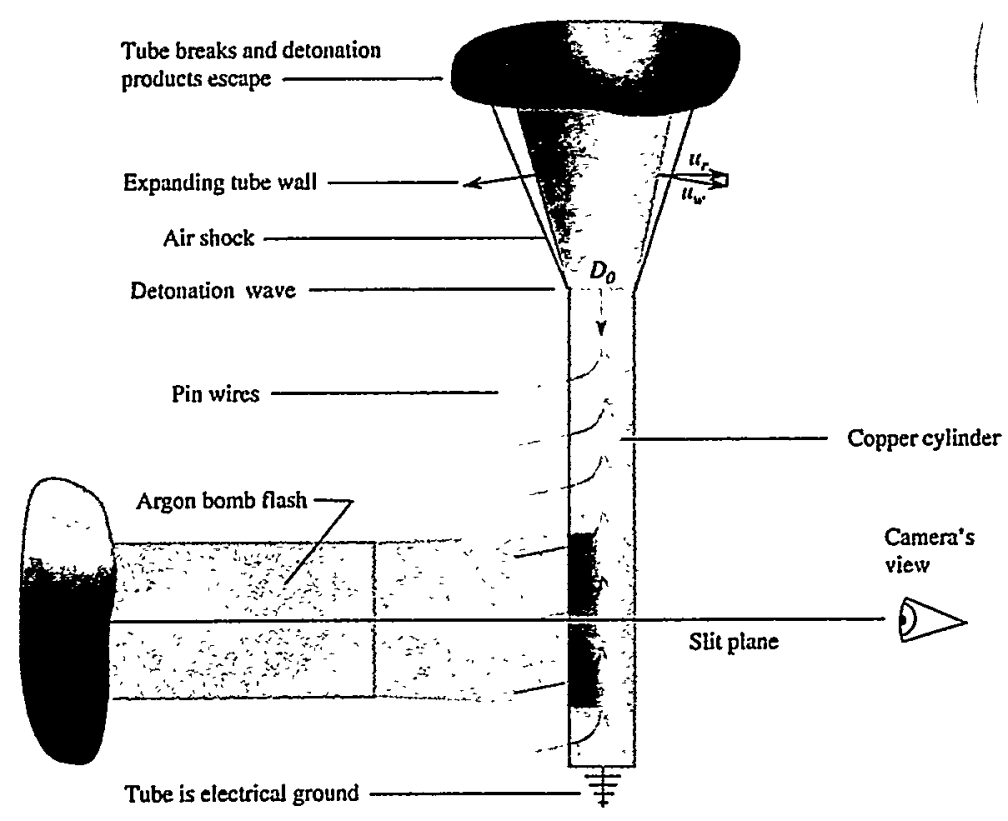

Schematic

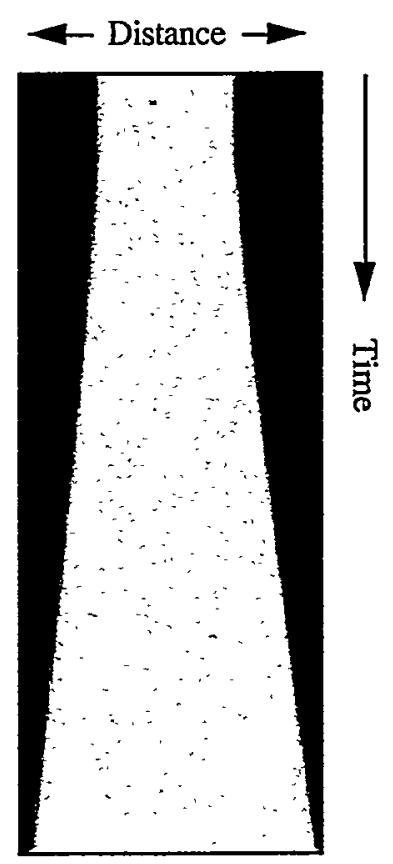

Streak Record

Figure 1. Cylinder test schematic and streak record (Provided by Larry Hill). 


\subsection{DEFINITIONS}

Annealing - heat treating the cylinder to a recrystallized, dead-soft condition.

Argon bomb (flash)-Used for backlighting the cylinder test in order to view the wall expansion in silhouette on the film record of the streak camera.

Cylinder clamp apparatus-Apparatus used to hold the HE-filled cylinder in place and compress the HE to the sum of the individual pieces.

Etching-process of dipping the cylinder in an acid solution for removal of oxides.

Fillet-a welding term, used to join two surfaces to one another.

Immersion density - the density of a material as measured by immersion in water.

Plywood blast shield - for slowing down blast products, it is attached near the top of the cylinder. Approximate dimensions are 8 in. to 10 in. diameter, $1 / 2$ in. thick, with a hole in the center just large enough to fit around the outside diameter of the cylinder.

Telephone pole - so named because the pin wires hang equidistantly between this pole and the cylinder, giving it the appearance of a telephone pole.

\subsection{GENERAL SPECIFICATIONS}

\subsection{Cylinder Material}

3.1.1 Material designation: Alloy 101, OFHC copper, $99.99 \%$ purity, $8.94 \mathrm{~g} / \mathrm{cm}^{3}$ density. Typical grain size of $25 \mu \mathrm{m}$ to $30 \mu \mathrm{m}$.

\subsection{Premachined (Initial) Cylinder Dimensions}

Nominal copper cylinder dimensions before machining:

\subsubsection{Length: 14 in.}

3.2.2 Outside Diameter (OD): 1.2 in.

3.2.3 Inside Diameter (ID): 1.0 in.

\subsection{Postmachined (Final) Cylinder Dimensions}

Final cylinder dimensions after machining are as follows, one may also reference drawing number 34Y-168189 in Appendix A. Machining procedures to meet this specification can be found in Appendix B.

3.3.1 Length: $11.800 \pm 0.002$ in.

3.3.2 OD: $1.2000 \pm 0.0005$ in.

3.3.3 ID: $1.00000 \pm 0.00025 \mathrm{in}$.

3.3.4 Wall Thickness: $0.10000 \pm 0.00025$ in.

3.3.5 Cylindricity: \pm 0.0002 in. 


\subsection{Cylinder Heat Treatment}

Once machined to final specifications, the copper cylinder is ready for annealing and etching. The annealing process (heat treatment) provides a dead-soft condition in the cylinder and relieves any stresses induced by machining and any residual work from initial fabrication. The dead-soft condition allows for maximum elongation and ductility of the material. Particular attention should be taken to avoid over- or under-annealing to prevent grain size growth. The etching process removes residual oxides from the cylinder exterior and slows oxidation of the material, which could potentially contribute to premature failure of the cylinder during expansion. The LANL heat treatment and etching procedure can be found in Appendix C.

\subsection{High Explosive Machining}

The HE is machined as a right circular cylinder. The OD of the HE should be machined to a custom fit, approximately 0.001 inch less than the $\mathrm{ID}$ of the cylinder, to achieve a nice slip-fit within the annulus of the cylinder without interference. The ends of each $\mathrm{HE}$ cylinder need to be flat and parallel to minimize air gaps after insertion into the tube and for good contact between the HE pieces. Cylinder tests using $\mathrm{HE}$ material for baseline experiments are machined to a 1-inch or 2-inch height. Stockpile return material is machined to a 1-inch height. Postmachined HE dimensions are as follows (units are in inches):

\subsubsection{Diameter: $0.9990 \pm 0.0005$}

3.5.2 Length: $1.000 \pm 0.005$ or $2.000 \pm 0.010$ (dependent upon application)

\subsection{Cylinder Test Assembly and Setup}

The following details are important to achieve consistent, successful results:

3.6.1 Maintain tight tolerances in the machining of the copper cylinder and the HE cylinders.

3.6.2 Careful observation of the metallurgy and heat treatment of the copper cylinder.

3.6.3 Load the HE within the tube slowly to allow captured air between the segments to escape.

3.6.4 Clamp the HE to the sum of the total heights of the individual $\mathrm{HE}$ cylinders to prevent the copper tube from failing at the joints between the explosive segments.

3.6.5 Ensure that an $\mathrm{HE}$ cylinder joint does not fall in the location of the slit.

3.6.6 Use extreme care to prepare and attach the pin wires to the tube, avoid damage to the pin wire insulation, check for continuity between the ends of the pin wires, check for shorts between the pin wires and ground (cylinder), and crimp the wires to the signal cables on the pin board.

3.6.7 Install a plywood blast shield to slow detonation products from impeding the view of the streak camera to the slit location on the cylinder.

3.6.8 During setup, align the cylinder on the shot stand perpendicular to the slit to achieve a symmetric breakout on the film record.

3.6.9 Typical shot data used by LANL are provided as a guide and include:

- Magnification: 0.33

- Writing speed: $3.0 \mathrm{~mm} / \mu \mathrm{sec}$

- Slit: single, 2 mil wide

- Lens: $480 \mathrm{~mm}$

- Still photo: $F \# 22$ at $1 / 60$ sec. with \#58 green filter

- Dynamic photo: F\#27 with \#58 green filter 
Details of the assembly and setup procedures typically used by LANL for their cylinder tests can be found in Appendix D. They are intended for use as a guide because other methods may also be used to meet this specification. A photograph of a cylinder test setup showing the cylinder being aligned with the alignment fixture in place, the plywood blast shield, argon bomb, pin board, sandbags, and the shot stand is shown in Figure 2 .

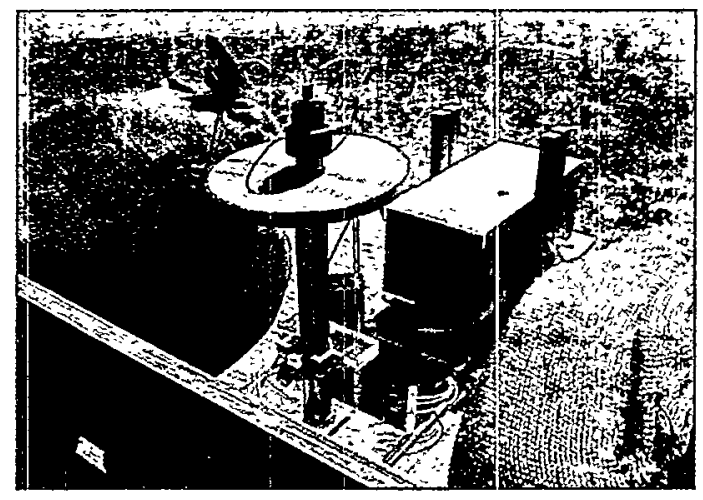

Figure 2. Cylinder test assembly on shot stand.

\subsection{Data Analysis}

Data analysis involves digitizing the wall expansion data (both the left and right sides) on an optical comparator. When these two nominally identical expansion profiles are overlaid, the agreement is typically excellent, though not quite within the random scatter of the data. The small discrepancy can be essentially removed by applying a correction for the primary sources of misalignment error. The resulting composite data record is then fit with an analytic form that smoothes through the early ring-up of the cylinder wall, and the fit is then differentiated to get the radial component of wall velocity. Half the radial velocity squared is close to the specific kinetic energy of the wall. This quantity evaluated at $19-\mathrm{mm}$ radial expansion is the $E_{19}$ standard cylinder energy. Another common figure-of-merit is the Gurney energy, which is approximately the kinetic energy of the explosive and the wall taken together, per unit mass of explosive. It is customary to quote $G_{19}$ as the Gurney energy evaluated at $19-\mathrm{mm}$ radial expansion. The detonation velocity, $D_{0}$, is determined from the slope of the best-fit line to the $\mathrm{x}-\mathrm{t}$ pin data.

A Mathematica ${ }^{\circledR}$ software program "Mathematica Analysis of Cylinder Test" (written by Larry Hill) is used to analyze cylinder test data. A sample program is attached in Appendix $\mathrm{E}$ for reference. Further information on the cylinder test analysis can be found in the Hill / Catanach report. ${ }^{1}$

\section{REFERENCE}

1. L. G. Hill and R. A. Catanach, "W-76 PBX 9501 Cylinder Tests," Los Alamos National Laboratory report LA-13442-MS (July 1998). 


\section{CYLINDER MACHINING PROCEDURE}

\section{B-1 Tooling Requirements}

The following tooling is recommended for machining the copper cylinders:

- Lathe

- Aluminum plug, 1.5 in. long by 1 -in. diameter

- Boring bar

- Reamers (0.980-, 0.985-, 0.990-, 0.992-, 0.995-, and 0.998-in. diameters)

- Hone

- Air bore gauge with indicator

- Mandrel, tapered (1-in. diameter by 12 in. long, A-2 tool steel, RC 59-62, tapered 0.0005 in./ft.)

\section{B-2 Machining Procedures}

B-2.1 Cut the cylinder to a length of 14 in.

B-2.2 Set the cylinder up on a lathe, and face the ends square.

B-2.3 Insert the aluminum plug within the ID of one end of the tube.

B-2.4 Using a boring bar, start boring the ID of the tube to about 0.005 in.

B-2.5 Ream the ID using the smallest possible reamer. Begin reaming approximately 0.001 in. at a time. Continue reaming the ID using a succession of increasing reamer diameters until the ID is within 0.0005 in. of the desired dimension specified in 3.3.

B-2.6 Remove the cylinder from the lathe, and set it up on the hone.

B-2.7 Hone the last 0.0005 in. off of the $\mathbb{I D}$. Periodically verify the $\mathrm{ID}$ along the entire cylinder length using the Air-Bore Gauge and Indicator.

B-2.8 Correct any deviation from the \pm 0.00025 -in. tolerance specified in 3.3 by rehoning the deficient area.

B-2.9 To machine the OD, slip the cylinder over the tapered mandrel. To expedite the fit, one may chill the mandrel in a freezer and heat the copper cylinder in boiling water just before slipping the cylinder on the mandrel. The contraction of the steel mandrel and expansion of the copper cylinder allows for a smoother fit of the mandrel within the cylinder $\mathrm{DD}$. When the materials return to room temperature, the mandrel and cylinder return to their original size, are joined, and the cylinder OD is ready to machine.

B-2.10 Set the mandrel/cylinder combination on a lathe and turn the OD between centers. Verify the cylinder $O D$ and correct any deviation from the 0.0005 -in. tolerance.

B-2.11 Once machining is complete, cut the cylinder ends to the length specified in 3.3.

B-2.12 Remove the cylinder from the mandrel by placing the assembly in boiling water. The highly conductive copper will expand at a faster rate than the steel mandrel and facilitate the removal. 


\section{CYLINDER HEAT TREAT AND ETCHING PROCEDURE}

\section{C-1 Annealing Process}

C-1.1 If annealing more than one cylinder, each cylinder must be heat-treated separately.

$\mathrm{C}-1.2$ Heat-treat at $350^{\circ} \mathrm{C}$ for one hour in a vacuum furnace to attain a fully recrystallized, dead-soft material.

C-1.3 Introduce argon gas into the furnace to facilitate heating and cooling of the cylinder.

\section{C-2 Etching Process}

C-2.1 Plug Cylinder Ends

Plug both ends of the cylinder with rubber stoppers to prevent affecting the interior surface of the cylinder.

C-2.2 Electro-polish

Electro-polish the outer cylinder surface by immersing the cylinder into a solution of $50 \mathrm{gm} / \ell$ sodium hydroxide, $25 \mathrm{gm} / \ell$ sodium carbonate at $80^{\circ} \mathrm{C}$ with a 10 -volt dc applied anodic current.

C-2.3 Acid etching

Remove residual oxides from the outer cylinder surface by acid-etching the exterior surface in a pickled 40 vol \% solution of hydrochloric acid.

C-2.4 Finish coat application After etching, apply a solution of $250 \mathrm{gm} / \ell$ chromic acid and $2.5 \mathrm{gm} / \ell$ sulfuric acid to the surface to slow oxidation.

C-2.5 Rinse and dry

Rinse the cylinder in deionized water and dry.

\section{C-3 Wrapping}

C-3.1 Wrap a 0.5-in.-wide strip of the cylinder in the region of the slit with cellophane to minimize oxidation and damage to this region. The slit location is approximately 7.4 in. from the initiated end of the cylinder (or $4.4 \mathrm{in}$. from the opposite end).

C-3.2 Wrap the entire cylinder with Kimwipes ${ }^{\circledR}$ or paper towels and place in a ZipLoc ${ }^{\circledR}$-type bag until ready for assembly to minimize damage and oxidation to the cylinder.

C-3.3 The cellophane wrap around the slit location must be removed by the firing site technician just before the test setup. 


\section{CYLINDER TEST ASSEMBLY PROCEDURE}

\section{D-1 Material Requirements}

- Polycarbonate base

- OFHC copper cylinder

- Cylindrical segments of high explosive

- Barco Bond $d^{\circledR}$

- Cylinder clamp apparatus

- Formvar ${ }^{\otimes}$ coated copper wire, 0.002-in. diameter

- Formvar $^{\circledR}$ stripper

- Telephone pole

- 11-pin pin board

- Wire crimps

- Kapton ${ }^{\circledast}$ tape

- Plywood blast shield

- P-16 plane wave lens with PBX 9404 or PBX 9501 booster

- PBX 9407 pellet (0.5-in. diameter by 0.5 -in. height)

- SE-1 detonator and adapter

\section{D-2 Cylinder Preparation}

D-2.1 Perform a visual inspection of the interior and exterior walls of the cylinder for any defects. Defects that could affect the performance of the cylinder expansion should be noted.

D-2.2 Keep the cylinder interior free of any infiltration of foreign matter that has a potential to introduce air pockets between the HE and the wall. The use of Kimwipes ${ }^{\Theta}$ is suggested to maintain cleanliness within the cylinder.

\section{D-3 HE Preparation}

D-3.1 Measure the density of the HE (by immersion) before insertion into the cylinder and document according to D-3.6.2.

D-3.2 Visually inspect the HE for defects (burrs, chips, cylindricity, flashing around edges due to pressing, etc.). Note any defects that could affect the performance of the HE or the final results of the test.

D-3.3 Visually inspect the ends of each HE piece for flatness. Kimwipes ${ }^{\otimes}$ can be used to gently rub over the $\mathrm{HE}$ to attain a smooth, flat surface.

D-3.4 Measure the height of each HE cylinder (to the nearest 0.0001 in.).

D-3.5 Calculate the total height of all the HE cylinders to be inserted into the tube.

D-3.6 Documentation Record the following information for each HE cylinder and keep with the test folder for each cylinder test:

D-3.6.1 Piece numbers

D-3.6.2 Immersion density $\left(\mathrm{g} / \mathrm{cm}^{3}\right)$

D-3.6.3 HE cylinder heights (in.)

D-3.6.4 Total height of all the HE cylinders (in.)

D-3.6.5 HE cylinder diameters (in.) 
D-4 Cylinder Scribe Marks for Pin Wires

D-4.1 Careful pin wire placement on the cylinder is critical for obtaining accurate $\mathrm{HE}$ detonation velocity. Before inserting the $\mathrm{HE}$ into the cylinder, very lightly scratch scribe marks on the exterior of the cylinder using a height gauge as shown in Figure 3. The scribe marks are used as reference for placement of the 2-mil-diameter pin wires.

D-4.2 Scribe the first mark (very lightly) 1.0 inch $(25.4 \mathrm{~mm})$ from the top end of the cylinder (the top end is furthest from the slit location). Lightly scribe the remaining nine marks in one-inch increments from the previous mark. Document the scribe mark locations as described in D-6.5.1 below.

\section{D-5 HE Insertion into Cylinder}

D-5.1 Insert the HE cylinders one at a time, end to end, into either end of the copper tube. Load the $\mathrm{HE}$ at a relatively slow rate to allow the air introduced between the pieces to evacuate. Document the piece number and the order in which each piece was inserted into the cylinder according to D-5.9.1.

D-5.2 Once all the HE is loaded, allow approximately 0.10 in. of $\mathrm{HE}$ to extend beyond each end of the tube. Lay the cylinder down on a piece of felt and glue a fillet on one end between the HE and the cylinder using Barco Bond $d^{\circledR}$. Allow sufficient time for the glue to dry before moving the assembly.

D-5.3 Verify that there is adequate room in the cylinder clamp apparatus for placing the HE-filled cylinder. Keep a finger on the unglued end and place the assembly in the clamp apparatus, unglued end face up. The clamp apparatus is shown in Figure 4 with an HE-filled cylinder assembly.

D-5.4 Place the brass die on the HE. Rotate the clamp knob in a clockwise direction until just making contact with the brass die.

D-5.5 Take into account the sum of the total height of all the individual pieces (Refer to D-3.6.4). Slowly rotate the clamping knob to apply constant pressure on the HE. Occasionally check the HE height using a height gauge. Clamp the $\mathrm{HE}$ until the equivalent combined total height of all the cylinders is reached.

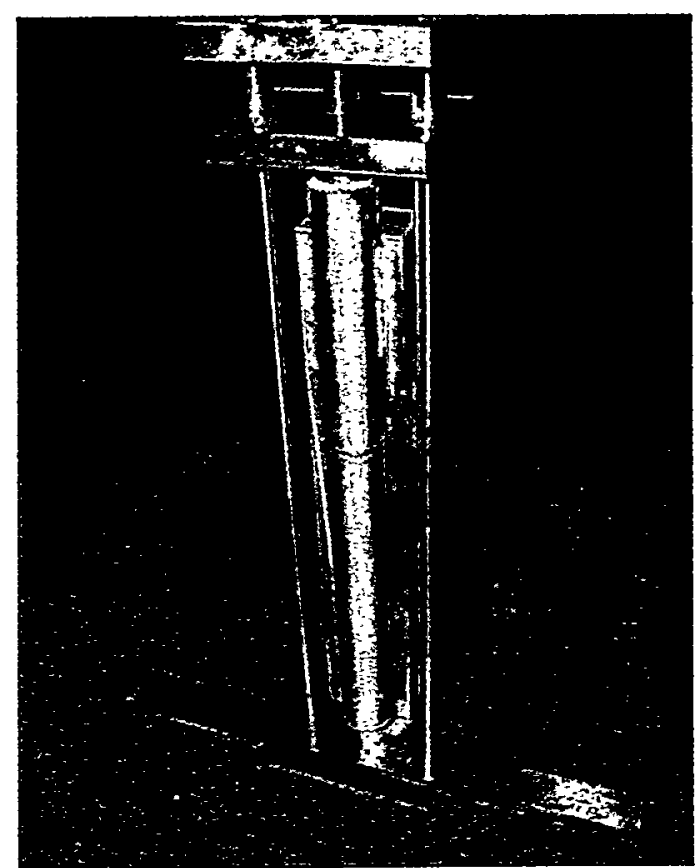

Figure 4. Cylinder test clamp apparatus (Designed by Herbert Harry). 
D-5.6 Once the documented sum of total height calculated from D-3.6.4 is reached, Barco Bond ${ }^{\circledR}$ a fillet between the top piece of $\mathrm{HE}$ and the end of the cylinder as shown in Figure 5.

D-5.7 Allow sufficient time for the glue to cure before removing the assembly from the clamp apparatus.

D-5.8 Once the glue is cured, slowly relieve the applied pressure and remove the assembly from the clamp and lay it flat on a piece of felt in preparation for pin wire application.

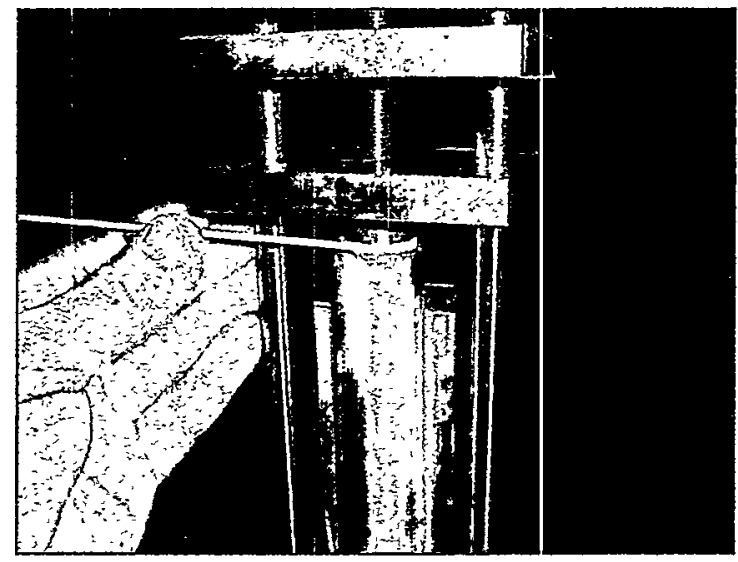

Figure 5. Gluing fillet between HE and cylinder.

D-5.9 Documentation

D-5.9.1 Document the order in which each HE cylinder was inserted into the tube, from top (\#1) to bottom (\#6 or \#12). The bottom HE cylinder is \#6 if using 2.0-in. cylinder heights or \#12 if using 1.0-in. cylinder heights. (The top $\mathrm{HE}$ cylinder is furthest from the slit region; the bottom is closest to the slit region.)

\section{D-6 Pin Wire Assembly}

D-6.1 Cut pin wires so that the longest wire (approximately 16 in.) is placed at the top scribe mark. Cut the remaining nine wires one inch shorter than the previous wire, (i.e., 15, 14, and 13 in., etc.).

D-6.2 Coat each wire $1 / 4$ in. from each end with Formvar ${ }^{\circledR}$ stripper. Allow the wires to soak for 5 minutes. Then, clean off the ends of each wire with a solvent.

D-6.3 Bend the wires into a check-mark shape on one end using a sharpened Popsicle $^{\Theta}$ stick (or equivalent) with an overhang of approximately $1 / 2$ in. Avoid pulling too hard so as not to break the pin wires.

D-6.4 Tape the apex of the check mark (using Kapton ${ }^{\circledR}$ tape) onto the cylinder, starting at the top scribe mark with the longest (16-in.) wire. Tape the remaining wires to their respective scribe mark on the cylinder as shown in Figure 6. Check each wire for accuracy of placement using an eyepiece with a graduated reticle, and document the deviation of each wire from its intended mark.

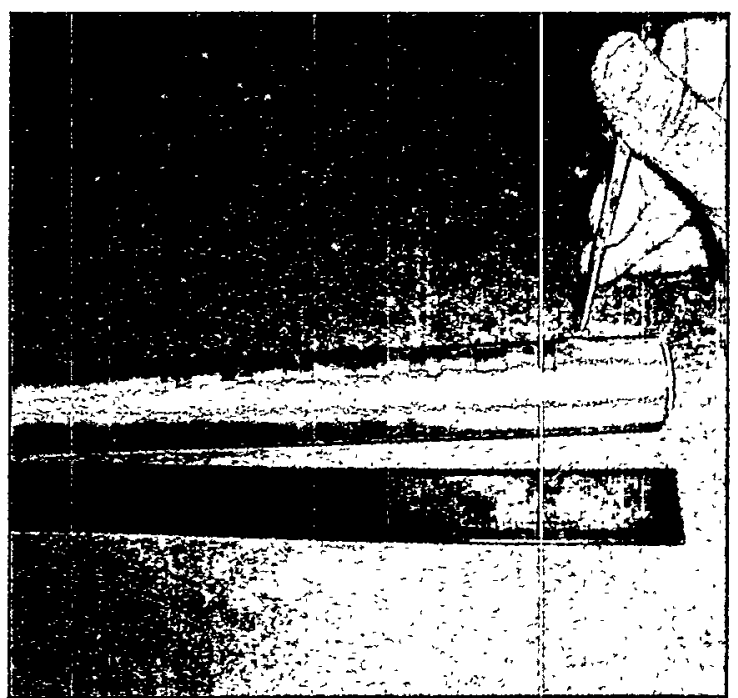

Figure 6. Taping pin wires onto the cylinder.

D-6.5 Documentation

D-6.5.1 Note the intended scribe locations for each pin (\#1 to \#10).

D-6.5.2 Note any deviation $( \pm 0.1 \mathrm{~mm})$ from its intended mark (for calculating an accurate run distance along the cylinder).

D-6.5.3 Calculate the actual run distance for each pin and note, using the top pin (\#1) as the reference. 
D-6.6 Starting with the top pin wire, use Kapton ${ }^{\circledR}$ tape to tape the wires to the telephone pole at approximately the same location as on the cylinder. Allow some slack in the wire between the telephone pole and the cylinder. For the pin wires located near the slit location: Tape the wires that are above the slit on the pole at approximately $1.5 \mathrm{in}$. above the slit location. Tape the wires that are below the slit on the pole at approximately $1.5 \mathrm{in}$. below the slit location. This is to allow room for the alignment fixture between the cylinder and the telephone pole.

D-6.7 Once pin wires are taped to the telephone pole individually, bundle the wires above the slit location and tape them as a unit to the pole. Do the same for the wires below the slit location.

D-7 Pin Board Assembly

D-7.1 Ensure that the signal cable braids are not touching the capacitors on the pin board and that the center conductor wire is not touching ground. Place a small dab of Barco Bond ${ }^{\otimes}$ on the braid where it enters the pin board and under the center conductor wire to prevent them from touching ground.

D-7.2 Set the pin board temporarily in its approximate final location on the base as shown in Figure 7. Hand measure the signal cables and cut the ends to within 1 in. of the telephone pole.

D-7.3 Strip the signal cables approximately 0.375 in. (or approximately one-half the length of the crimpers that will be attached to the end of the cable). The other one-half length of the crimper is for inserting the pin wires.

D-7.4 Insert and crimp the wires individually into the crimpers attached at the end of the signal cables from the pin board.

D-7.5 Attach the pin board ground wire to the cylinder.

D-7.6 Using an ohmmeter, check continuity between the end of the pin wires on the cylinder and the end of the signal cables on the pin board as shown in Figure 8.

D-7.7 Note on the pin board the corresponding pin wire number\#1 (top), \#10 (bottom)-respective to each signal cable.

D-7.8 Bundle the signal cables and strap them together with cable ties.

D-7.9 Glue the pin board to the base. Fan out (separate) the end of each signal cable. Tape each cable to the base near the telephone pole.

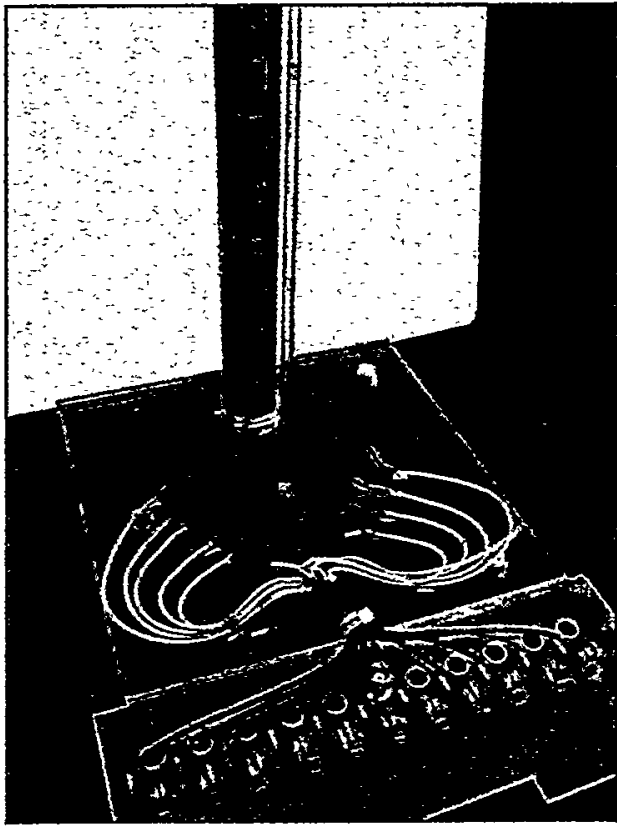

Figure 7. Pin board, cylinder, and telephone pole on polycarbonate base.

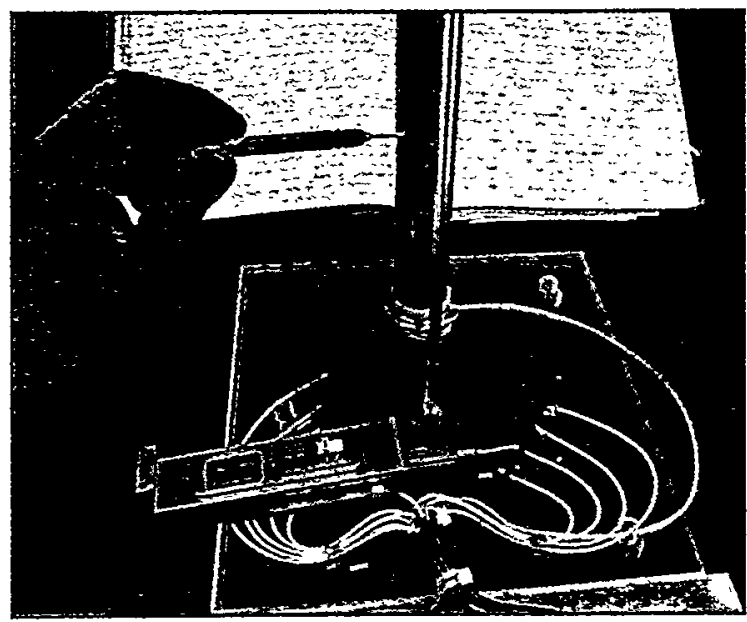

Figure 8. Checking pin wires for continuity. 


\section{D-8 Miscellaneous}

D-8.1 Attach the plywood blast shield near the top of the cylinder.

D-8.2 Insert one 0.5-in.-diameter by 0.5 -inlong PBX 9407 pellet into an SE-1 adapter and Barco Bond ${ }^{\circledR}$ the detonator adapter to the top of the plane wave lens (PWL).

D-8.3 Center and Barco Bond ${ }^{\circledast}$ the PWL on top of the assembly. A photograph of a typical cylinder test assembly before setup on the shot stand is shown in Figure 9. (Note: A booster may be required between the PWL and the cylinder $\mathrm{HE}$. See Figure 2 for an assembly with a booster).

D-8.4 For alignment of the tube on the shot stand, LANL uses an alignment fixture temporarily attached on the cylinder at the slit location (approximately 4.4 inches from the bottom of the cylinder). The assembly

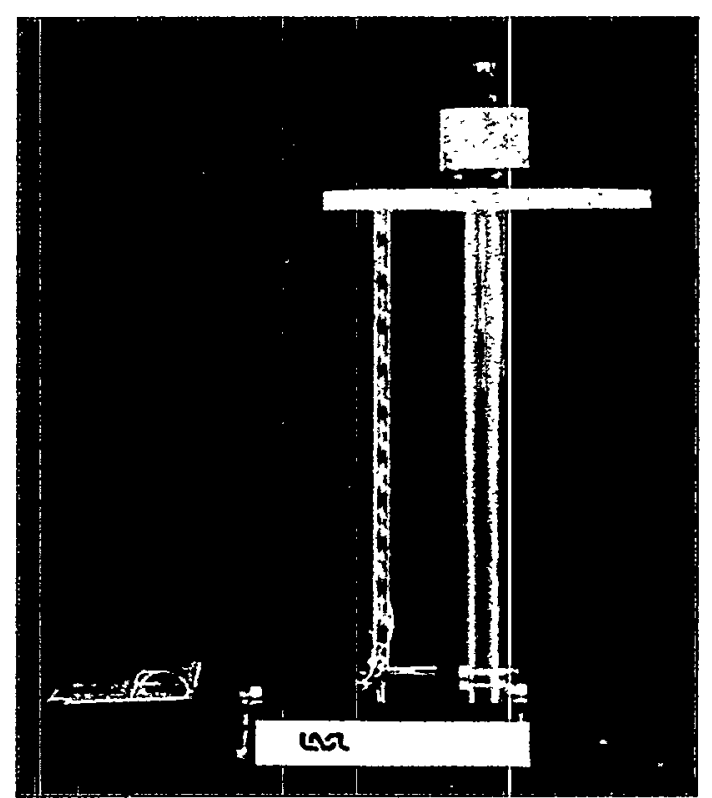

Figure 9. Typical cylinder test assembly. is then aligned using the cross hairs scribed on the alignment fixture.

D-8.5 Once alignment is completed and just before firing, remove the fixture, being careful to avoid cutting any of the pin wires.

\section{D-9 Argon Flash Charge Assembly}

D-9.1 Assemble a 12-in. long by 5/2/2-in. square (approximately) box using 0.75-in. lumber internally lined with aluminum foil. An assembled argon flash charge is shown in Figure 10.

D-9.2 Drill a 0.25-in.-diameter hole on one side to insert the tubing for the Argon gas.

D-9.3 Squeeze a line of $R T V^{\circledR}$ sealant completely around the edges of one end of the box.

D-9.4 Seal the end of the box by placing a 0.25 -in. sheet of glass over the $R T V^{\circledR}$.

D-9.5 Cut a sheet of drafting Mylar the same size as the glass. Glue the Mylar on the glass.

D-9.6 On the other end of the box, glue a 4-in. square by 1-in.-thick slab of Comp B explosive.

D-9.7 Place a fillet of $R T V^{\circledR}$ between the HE and the box.

D-9.8 Insert one 0.5 -in.-diameter by 0.5 in.-long PBX 9407 pellet into an SE1 adapter.

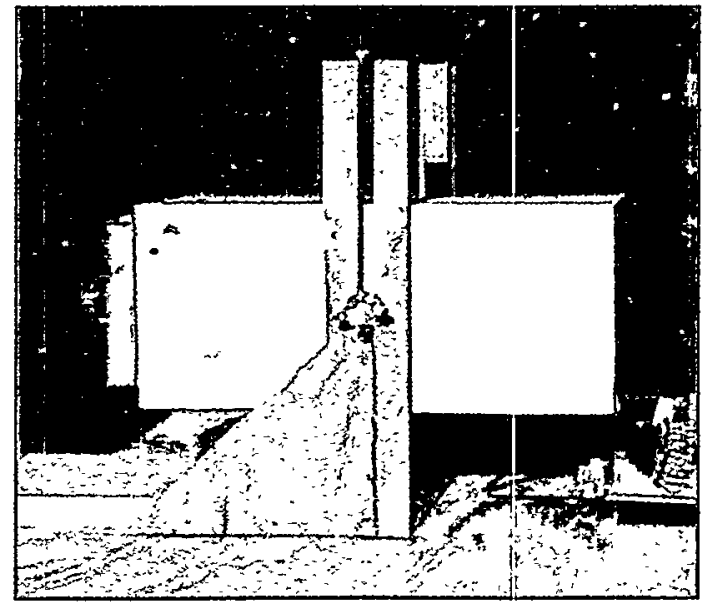

Figure 10. Argon flash charge.

D-9.9 Glue the SE-1 adapter in the middle of the Comp B using a Barco Bond ${ }^{\otimes} /$ hardener mixture. Use an equivalent one-to-one mixture. 


\section{Mathematica Analysis of Cylinder Test Shot \# 15-2861}

\section{Version: 1.3}

\section{Date: $5 / 1 / 98$}

\section{By: Larry Hill, Group DX-1, LANL}

\section{E-1. Notebook and Analysis Information (Read this first.)}

This program operates interactively. The user is prompted for information and must make decisions based on intermediate results. The commands should be executed in sequence. The cells that are highlighted with a box require the user to supply information before executing the command.

The program assumes that the cylinder expansion data are read in a particular way. The film is aligned with the writing direction horizontal, with time increasing to the right. The spatial film coordinate $\mathrm{x}$ is read as a function of the time film coordinate $y$. The units on the optical comparator should be set to millimeters. Both sides of the data trace are read into separate files. The time origin is set to the "jump-off" point, where the tube expansion begins. The time origin may be set seperately for each side, or it may be left the same for each side. (The two time origins will be mutually adjusted for optimum agreement.)

It is important not to remove or adjust the film between the top and bottom readings, and the two sides should be read with little delay in between so as to minimize dimensional changes due to shifts in ambient temperature. As read, the upper trace " $\mathrm{U}$ " will have positive $\mathrm{x}$-values, and the lower trace " $\mathrm{L}$ " will have negative $\mathrm{x}$-values.

The pin data are entered manually in Section 10, according to the instructions there.

Date and version information:

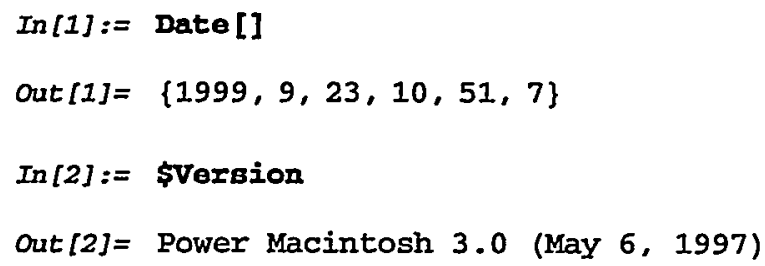

This command turns off spelling error warning messages:

$\operatorname{In}[3]:=$ Off [Genera]: :spel]1] 


\section{E-2. Shot Information}

Shot number: 15-2861

Shot date: $\quad 9 / 21 / 98$

Description: PBX 9502

Temperature: Ambient

Shot parameters:

Specify the reference magnification, corresponding to the tube o.d.:

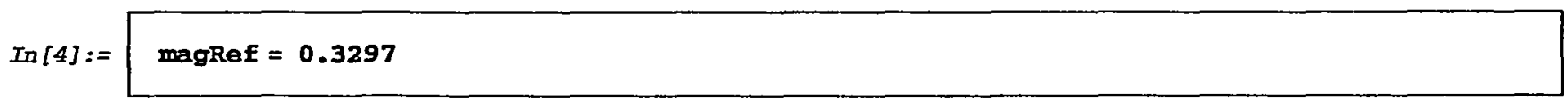

Out $[4]=0.3297$

Specify the writing speed (assumed to be constant across the film):

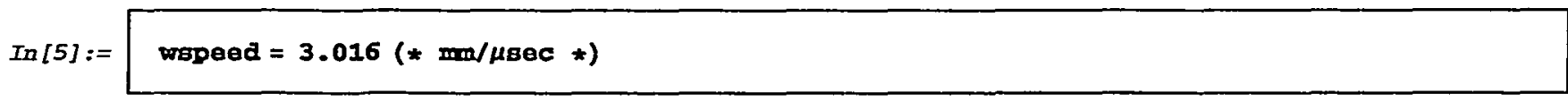

$\operatorname{Out}[5]=3.016$

Specify the outer radius of the tube:

$\operatorname{In}[6]:=\operatorname{RO}=15.24(* \operatorname{Im} \star)$

Out $[6]=15.24$

Specify the inner radius of tube:

$\ln [7]:=\quad I 0=12.71(* \operatorname{mm} *)$

Out $[7]=12.71$

Specify the density of the tube:

$\operatorname{In}[8]:=0 \%=8.94(*$ g/cc $t)$

Out $[8]=8.94$

Specify the initial HE density: 
CYLINDER TEST

$\operatorname{In}[9]:=\rho 0=1.889(* \mathrm{~g} / \mathrm{CC} *)$

$\operatorname{out}[9]=1.889$

\section{E-3. Film Data}

This command sets the directory to where the data files reside. Specify the path:

$\operatorname{In}[10]:=$

SetDirectory [

"HardDrive:StandardPests : Cylinders : Shots-Cylinders : 9502 : w-80:15-2861"]

out $[10]=$ HardDrive:StandardTests :Cylinders :Shots-Cylinders : $9502:$ W-80:15-2861

These two commands read the data files. Files are identified by $U$ for "upper" and $L$ for "lower," but it is arbitrary which is which. Recall that $x$ is the spatial film coordinate and $y$ is the temporal film coordinate. Specify the file names:

In $[11]:=$ dataUyx $=$ Readrist ["15-28610.rac", \{Real, Real\}] ;

$\operatorname{In}[12]:=$ dataryx = Readrist ["15-28611.rac", \{Real, Real\}];

\section{E-4. Conversion to Real Space-Time}

This is the mapping to real space-time coordinates. Here $t$ denotes time and $e=R-R 0$ denotes the radial expansion of the outer tube surface relative to its initial position. The term $R$ is used to denote the outer radius, and $r$ is used to denote the inner radius.

The magnification will generally vary slightly across the width of a streak camera. The following formula is a correction for the Los Alamos model 72 B camera and a particular lens (Rodenstock $800 \mathrm{~mm}$ ). One may substitute different corrections, or assume a constant magnification, as appropriate. This equation describes the measured magnification, normalized by the centerline value, as a function of the spatial film coordinate $\mathrm{x}$ measured from the center of the film:

$\operatorname{In}[13]:={ }^{*} \mathrm{MF} 480\left[x_{-}\right]=1+\frac{1.0440 x^{2}}{10^{5}}$

Out $[13]=1+0.00001044 x^{2}$

This is the actual magnification, which makes use of the reference magnification magRef measured at an $\mathrm{x}$ position R0*magRef:

$\operatorname{In}[14]:=\operatorname{mag}\left[x_{-}\right]=\frac{\operatorname{magRef} \mathrm{MF} 480[x]}{\operatorname{LF} 480[\text { R0 magRef] }}$

out $[14]=0.329613\left(1+0.00001044 x^{2}\right)$

This is the mapping function to real time and space coordinates: 
$\operatorname{In}[15]:=$ FWte $\left[w_{-}\right]:=\left\{\frac{m[1 \rrbracket}{\text { wopeed }}, \frac{\mathrm{Abg}[w \llbracket 2 \rrbracket]}{\operatorname{mag}[w[2 \rrbracket]}\right\}$

Apply the mapping to the data files:

In $[16]:=$ dataUte $=$ Lap [FNte, datadyx] ;

datarte $=$ Map [FNte, dataIyx];

This is the uncorrected combined data set:

$\operatorname{In}[17]==$ datauLțe = datadte U datalte;

This is a plot of the uncorrected combined data set. Specify the shot number for the title:

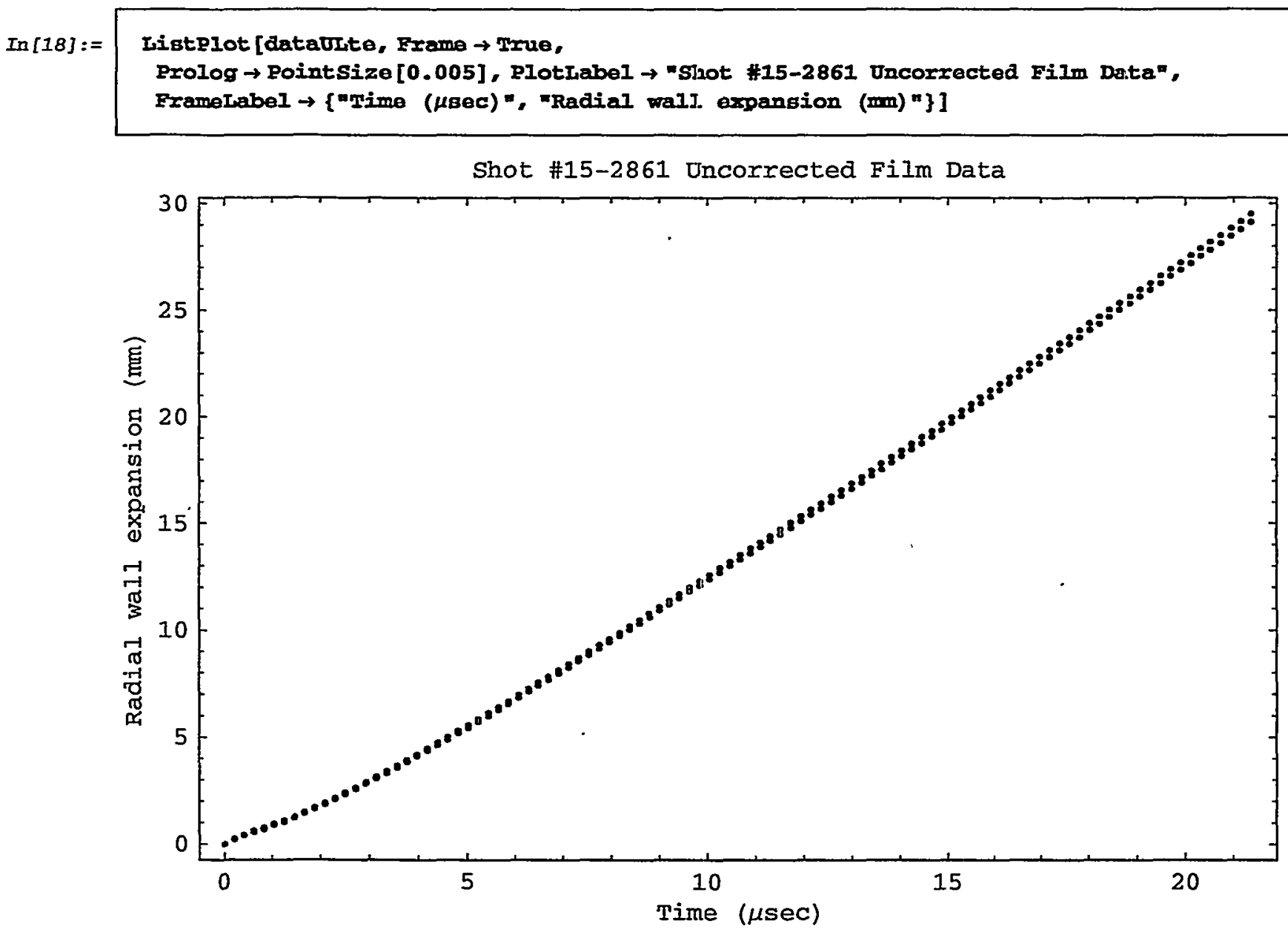

out $[18]=$ - Graphics - 


\section{E-5. Tilt and Time-Shift Correction}

The most prevalent alignment errors are (1) the slit not being perfectly normal to the writing direction, and (2) the slit not being perfectly square with the shot. Both of these errors cause time errors proportional to the radius. For most shots, such errors are greater (though often only slightly so) than the background noise. One may remove this error by comparing both sides of the record, and using the fact that the error is antisymmetric about $R=0$.

It is equivalent, and simpler, to work with the time as a function of expansion, $t[e]$, rather than of radius. This just introduces a relative shift in the time origins, which is readily accounted for. These commands transpose the data:

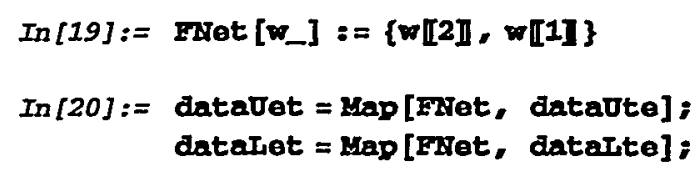

We now perform an interpolated fit to the data in order to subtract the two data sets:

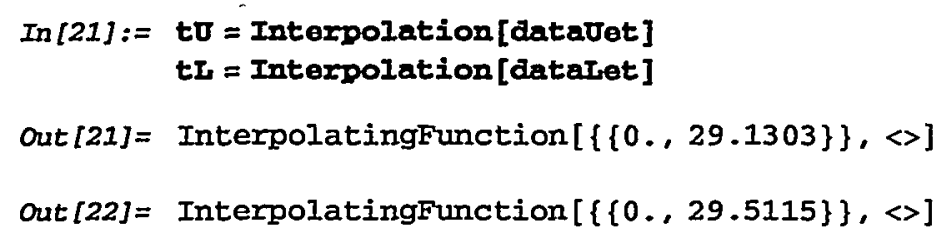

Find maximum time and radius values for plotting. Tmax is the maximum time of the combined data set:

In $[23]:=\operatorname{Tmax}=\operatorname{Max}[$ Thread [dataULte] [1]]

Out $[23]=21 \cdot 3747$

The variable emaxlst is the maximum expansion of the side that breaks first:

$\operatorname{In}[24]:=\operatorname{emax} 1 \mathrm{gt}=\operatorname{Min}[\operatorname{Max}[\operatorname{Thread}[$ dataUte] [2]], Max[Thread [dataLte] [2I]]

Out $[24]=29.1303$

The variable emax $2 \mathrm{nd}$ is the maximum expansion of the side that breaks second:

In $[25]:=$ amaxe2nd $=\operatorname{Hax}[$ Thread [dataULte] [2]]

Out $[25]=29.5115$

This is a plot of the two interpolation functions for time as a function of expansion. Specify the shot number for the title: 


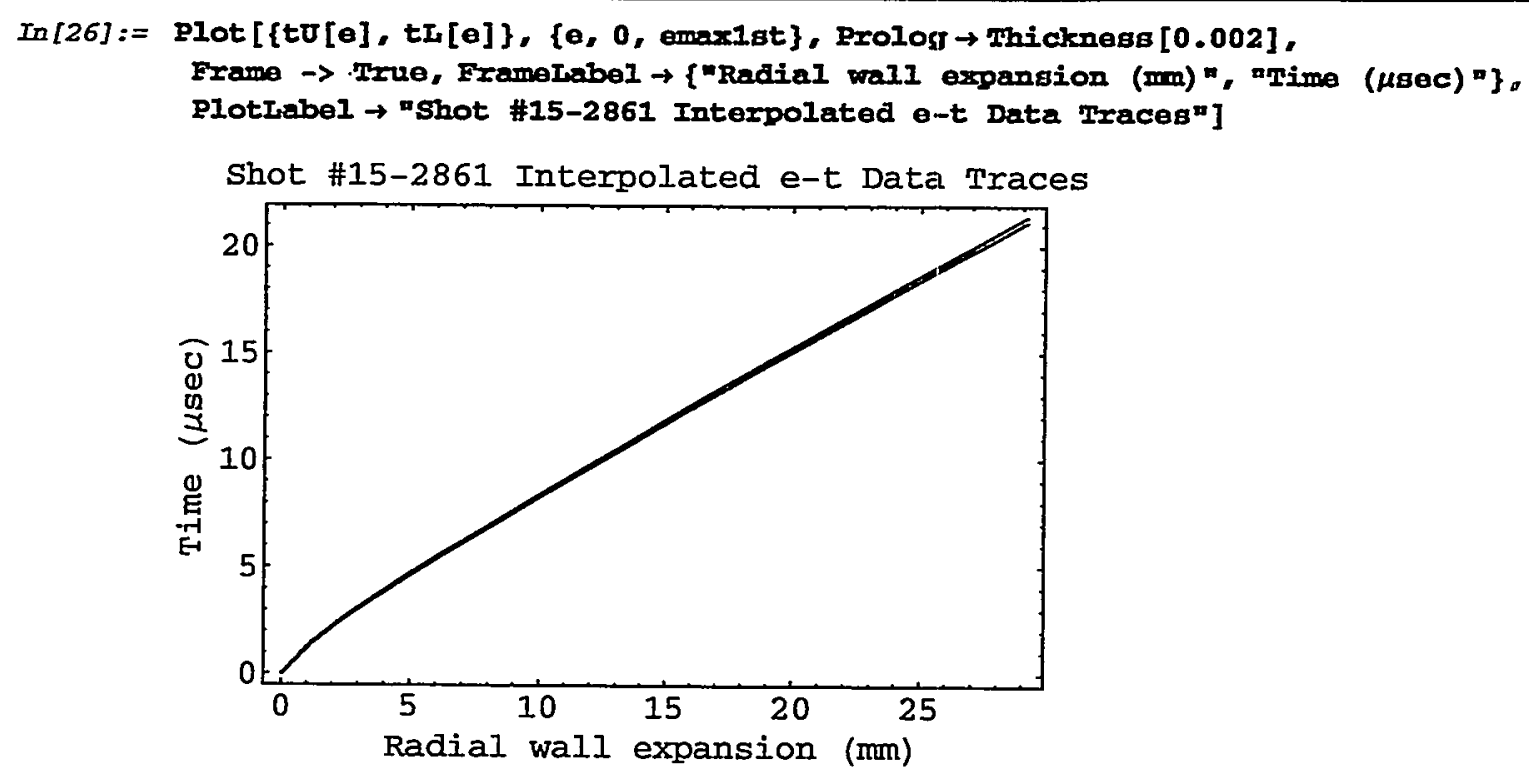

Out $[26]=$ - Graphics -

This is the time difference between the two traces as a function of radial wall expansion:

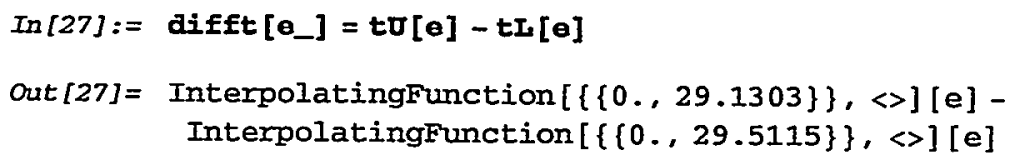

This is a plot of the difference between the two above interpolation functions. Specify the shot number for the title:

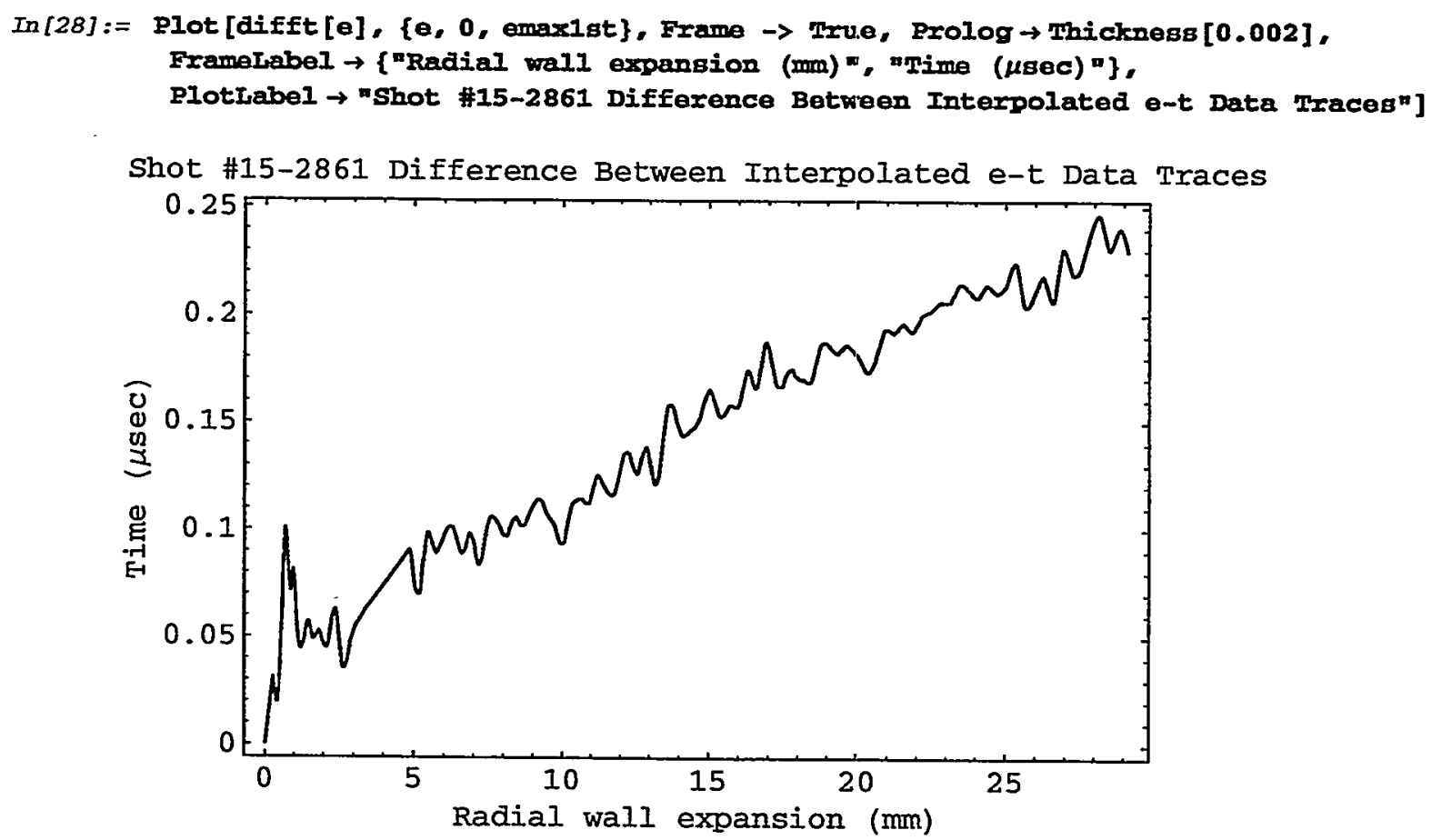

Out $[28]=$ - Graphics - 
The premise is that the above difference will be basically linear (with quite a bit of noise superimposed). The intercept is the relative error between the two time origins, and the slope is the relative tilt. Often the data near the origin (which tends to be a bit erratic) will deviate from the overall linear trend and will need to be pruned, so as to best fit the linear portion of the curve. You will need to look at the curve and decide which portion (if any) to cut off. Specify echop, the wall expansion below which the fitting data will be dropped:

$\operatorname{In}[29]:=\quad$ echop $=2$

Out $[29]=2$

The following commands generate a pruned list of points from the above difference function and fit a line to it:

In $[30]:=\operatorname{dateDiff}=\operatorname{Table}[\{e, \operatorname{difft}[e]\},\{e$, echop, emaxist, 0.1$\}]$

This command performs a linear fit to dataDiff:

In [32]:= fitDifft [o_] = Fit [dataDiff, $\{1,0\}, e]$

out $[32]=0.0447923+0.0068711 \mathrm{e}$

This is a plot of the time difference data between $e-t$ records and the linear fit to it. Specify the shot number for the title:

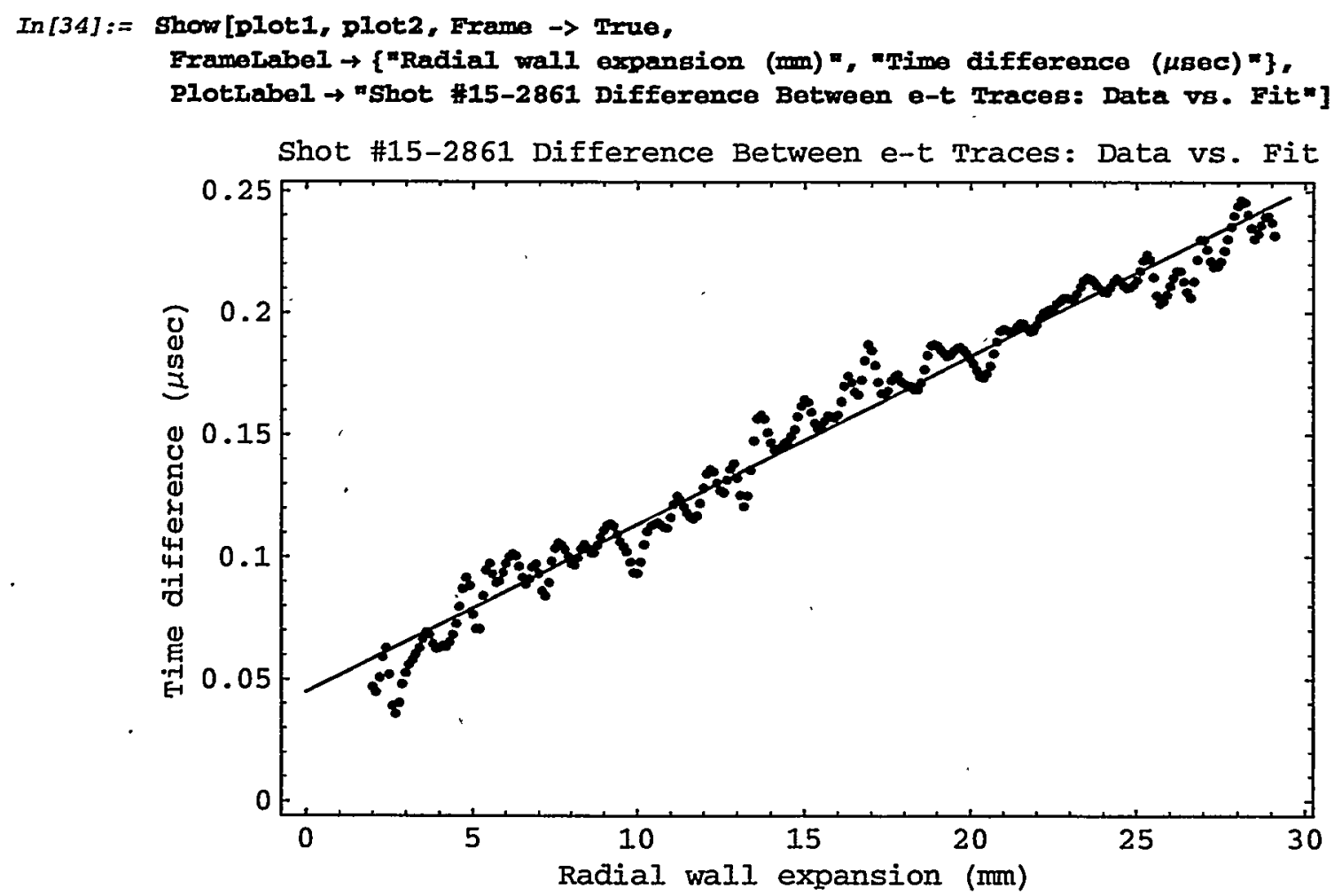

out $[34]=$ - Graphics -

The following commands apply the correction, determined by the above fit, to the data points. The data are also transposed back to $e$ as a function of $t$ at the same time. 


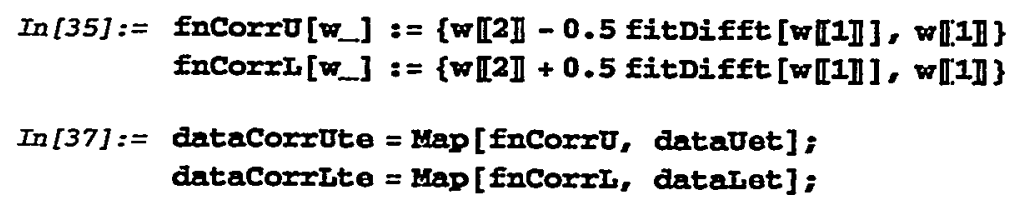

The combined corrected data set is:

In $[38]:=$ datacorrte $=$ dataCorrote U datacorrite;

The time origin shift just performed will generally give a point or two with negative time values. It is desirable to shift the combined set to make the first data point correspond to zero time; otherwise, the fitting form will be complex in that region. The following command shifts the time origin so that the first value is zero:

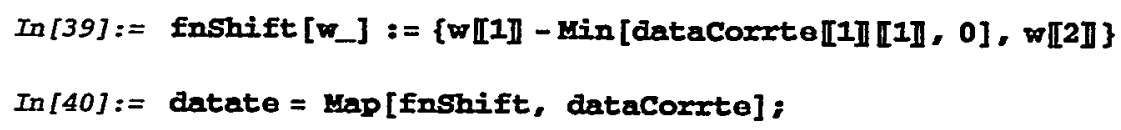

This is a plot of the corrected radial wall expansion data. Specify the shot number for the label:

Shot \#15-2861 Corrected Film Data

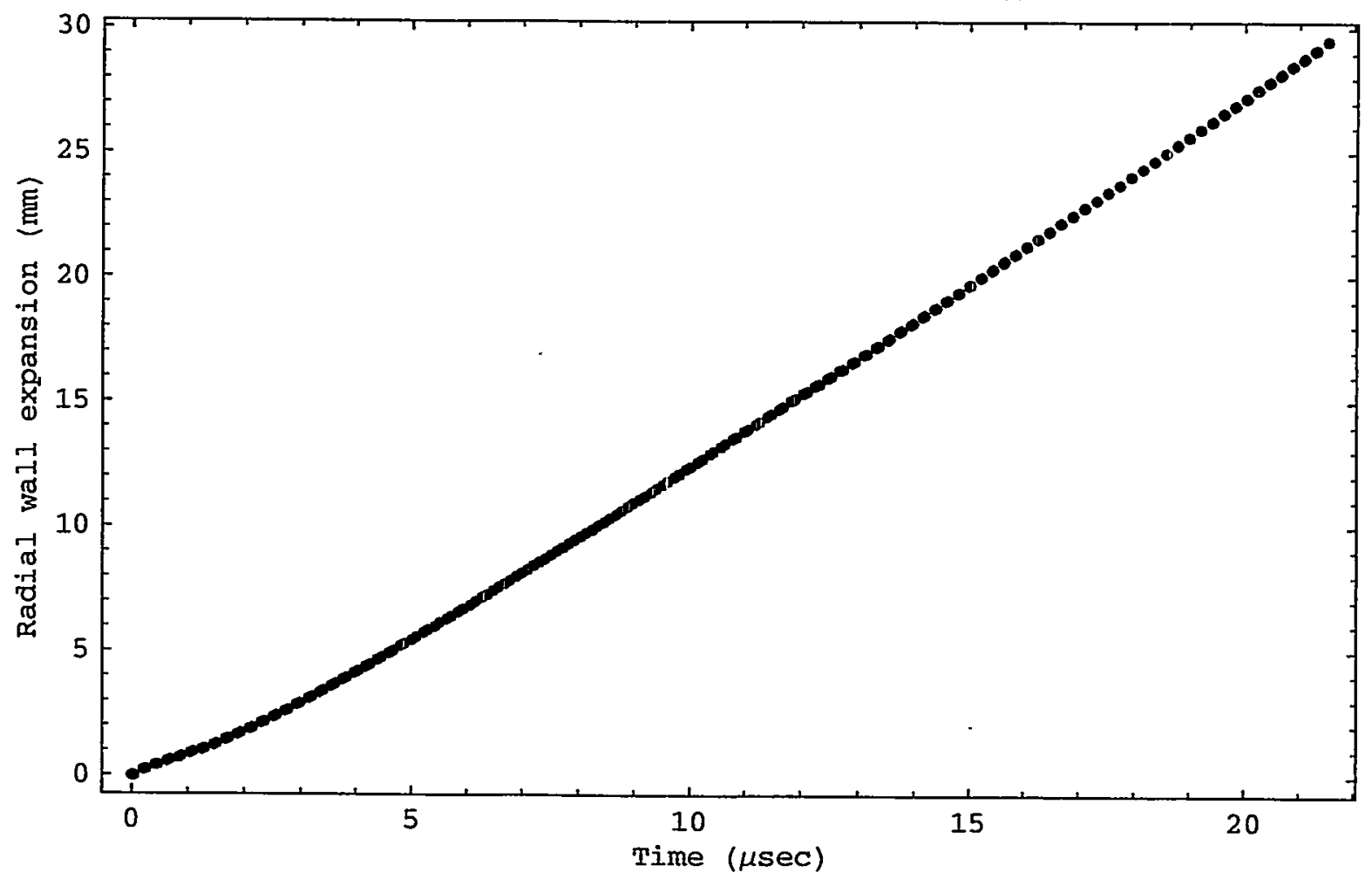

Out $[41]=$ - Graphics -

This set of commands is a routine for writing data to an external file. 


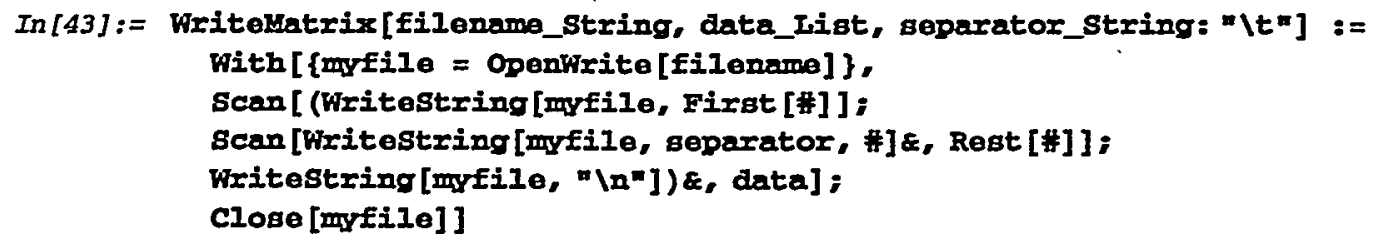

Write the final data set to a file, so that it may be used outside this notebook:

In [44] := Writekatxix ["15-2861te.dat", datate]

out $[44]=15-2861$ te $\cdot$ dat

\section{E-6. Data Fitting}

Load the NonlinearFit package:

$\operatorname{In}[45]:=$ HeedB $\left[{ }^{\text {"Statistics }}{ }^{\text {NonlinearFit }}{ }^{\prime}\right]$

\section{- 6.1 Fitting Form}

Use the following rational polynomial fitting form, where vro is the asymptotic radial velocity, ar 0 is the initial radial acceleration, t 0 is a virtual fit origin, and $\omega$ is a fitting parameter:

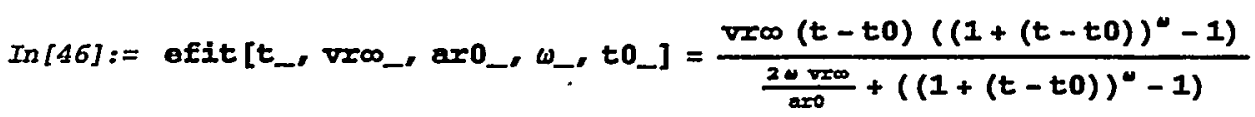

$$
\begin{aligned}
& \operatorname{out}[46]=\frac{\left(-1+(1+t-t 0)^{\omega}\right)(t-t 0) \text { vro }}{-1+(1+t-t 0)^{\omega}+\frac{2 \operatorname{vxc\omega } \omega}{\operatorname{arc} 0}}
\end{aligned}
$$

\section{- 6.2 First Pass}

It is necessary to first get an approximate fit using a reduced number of parameters; otherwise, the algorithm may not converge to the correct answer. A second pass will then fit all the parameters simultaneously.

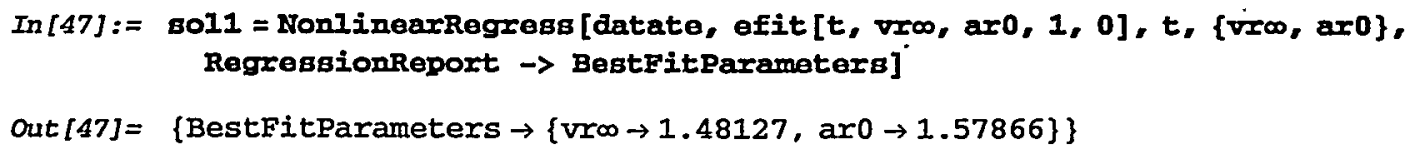

These commands assign the fitted parameters to variables:

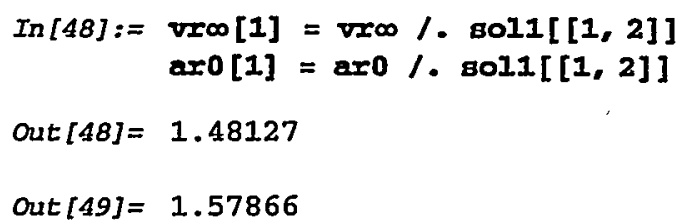

These commands compute the10x fit residuals: 


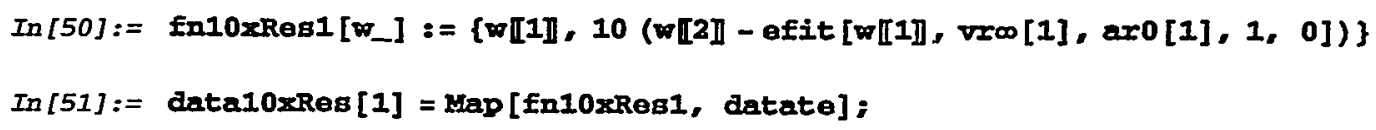

This is a plot of the first pass 10x fit residuals. Specify the shot number for the label:

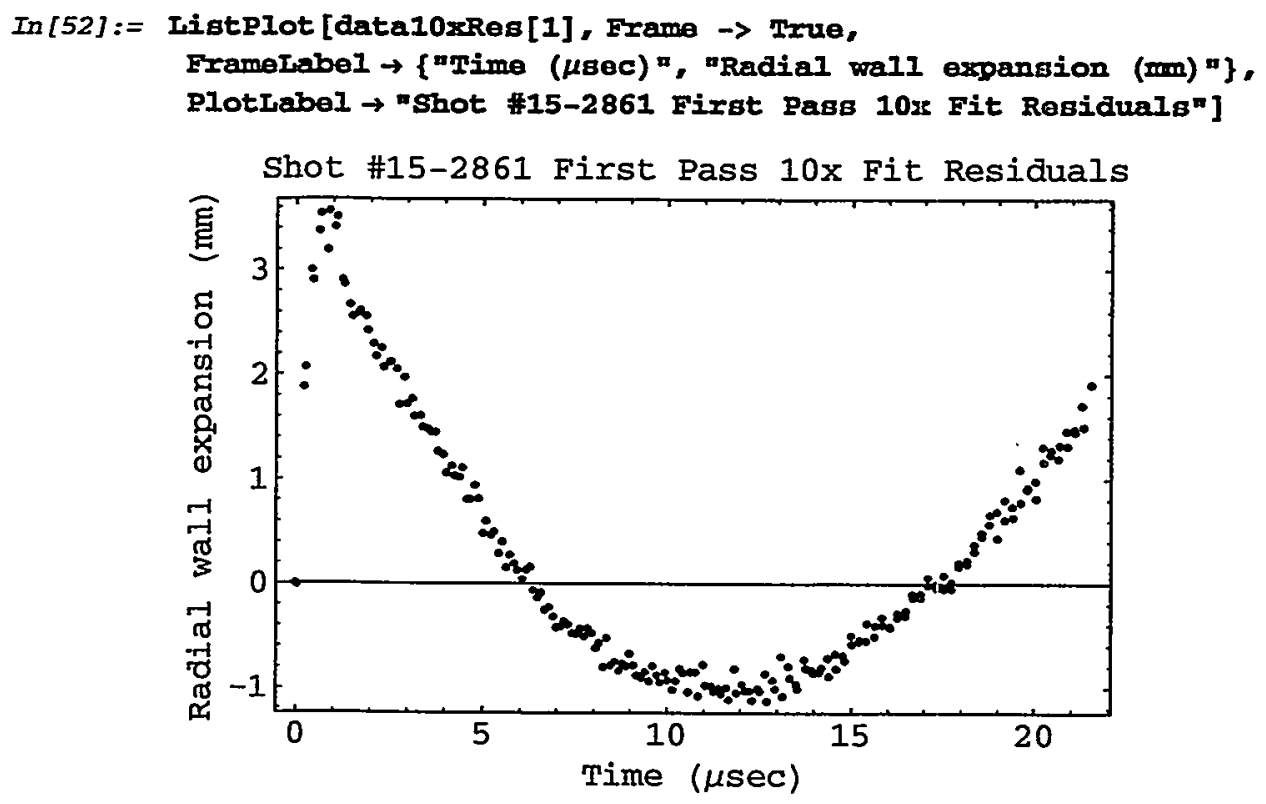

out [52] = - Graphics -

\subsection{Second Pass}

Now use the parameters from the first pass as starting values, and allow a finite virtual origin t0 and an arbitrary exponent $\omega$. The goal is for the fit residuals to oscillate symmetrically around zero. In some cases, it may be desirable to chop off some of the initial data points when fitting, to give the fit the desired properties. In other cases, the tube may break near the end of the record. In that case, the tube appears to accelerate because of the smoke squirting out. If both sides of the tube are read, the record may also become asymmetric following break up. (A rule of thumb is that the tube usually expands to about three times its initial diameter before breaking.) If it is apparent that the tube is breaking, the associated data points should be truncated and the data should be refit.

\section{- 6.3.1 Truncated Data Set}

The parameter tfitmin is the time below which the data is to be cropped for fitting. Its value should be zero initially and modified only if necessary to achieve the desired fit. Specify tfitmin: In $[53]:=\quad$ tfitmin $=0$ (* nominal value zero $*)$

out $[53]=0$

The parameter tfitmax is the time above which the data is to be dropped for fitting. Its value should be Tmax initially, and modified only if there is evidence that the tube broke before the end of the record. Specify tfitmosx: 
In $[54]:=$ tfitmax $=\operatorname{Tmax}(*$ nominal value Tmax *)

Out $[54]=21 \cdot 3747$

These commands chop low and high parts separately:

In $[55]:=$ datatechopLo $=$ Drop [datate, Floor [Iength [datate] *tfitmin / Tmax] ]; datatechopHi $=\operatorname{Drop}[$ datate, - Floor [Iength [datate] $*($ Thax - tfitmax $) /$ Tmax] $]$;

The desired "chopped" file is the intersection of the above two lists:

In $[56]:=$ datatechop = Intersection [datatechoplo, datatechopHi] ;

\subsubsection{Final Fit}

This fit optimizes all the fitting parameters simultaneously, starting with reasonable guesses:

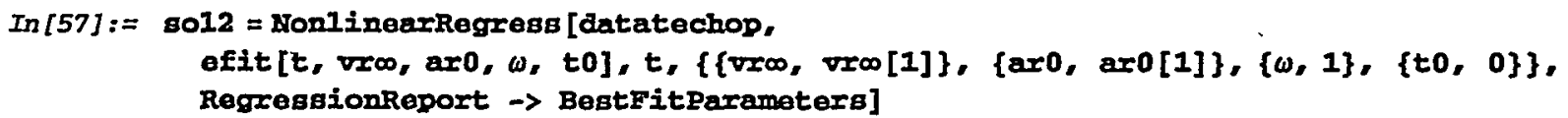

Out $[57]=$ BestFitParameters $\rightarrow\{v r \infty \rightarrow 1.60538$, aro $\rightarrow 1.28423, \omega \rightarrow 0.749857, t 0 \rightarrow-0.471362\}\}$

These commands assign the fitted parameters to variables:

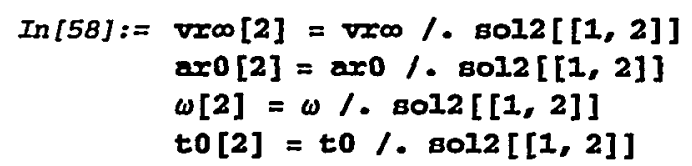

Out $[58]=1.60538$

Out $[59]=1.28423$

Out $[60]=0.749857$

Out $[61]=-0.471362$

\section{- 6.3.3 Examination of Fit}

Now compute the residuals of the second fit. Examine the residual pattern over the whole range, even if the fitting file was truncated:

$\operatorname{In}[62]:=\operatorname{fn} 10 x \operatorname{Res} 2[w]:=\{w[1], 10(w[2]-\operatorname{efit}[\mathrm{w}[1], \operatorname{vro[}[2], \operatorname{arc}[2], \omega[2], t 0[2]])\}$

In $[63]:=\operatorname{data10\times ReB}[2]=\operatorname{Map}[$ fn10xRes2, datate $]$;

This is a plot of the second pass $10 x$ fit residuals. These should look significantly better than the first. Specify the shot number for the label: 
In $[64]:=$ plot4 = IistPIot [ata10xRes $[2]$,

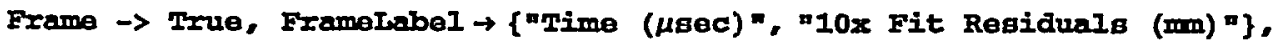

PlotIabel $\rightarrow$ "Shot \#15-2861 Second Pass 10x Fit Residuals"]

Shot \#15-2861 second Pass 10x Fit Residuals

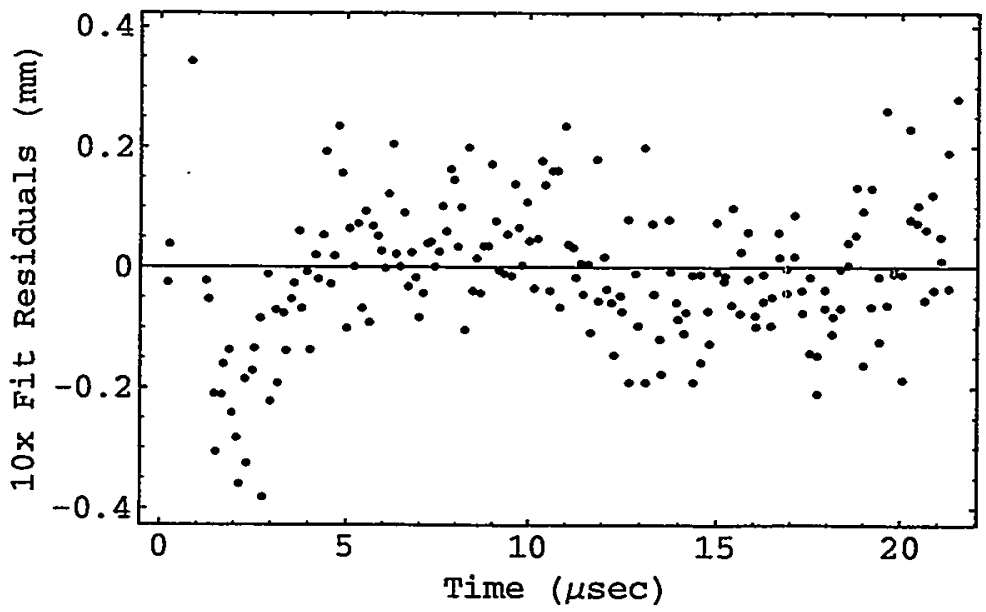

out $[64]=-$ Graphics -

This is a plot of the corrected radial wall expansion data, fit, and 10x fit residuals. Specify the shot number for the label:

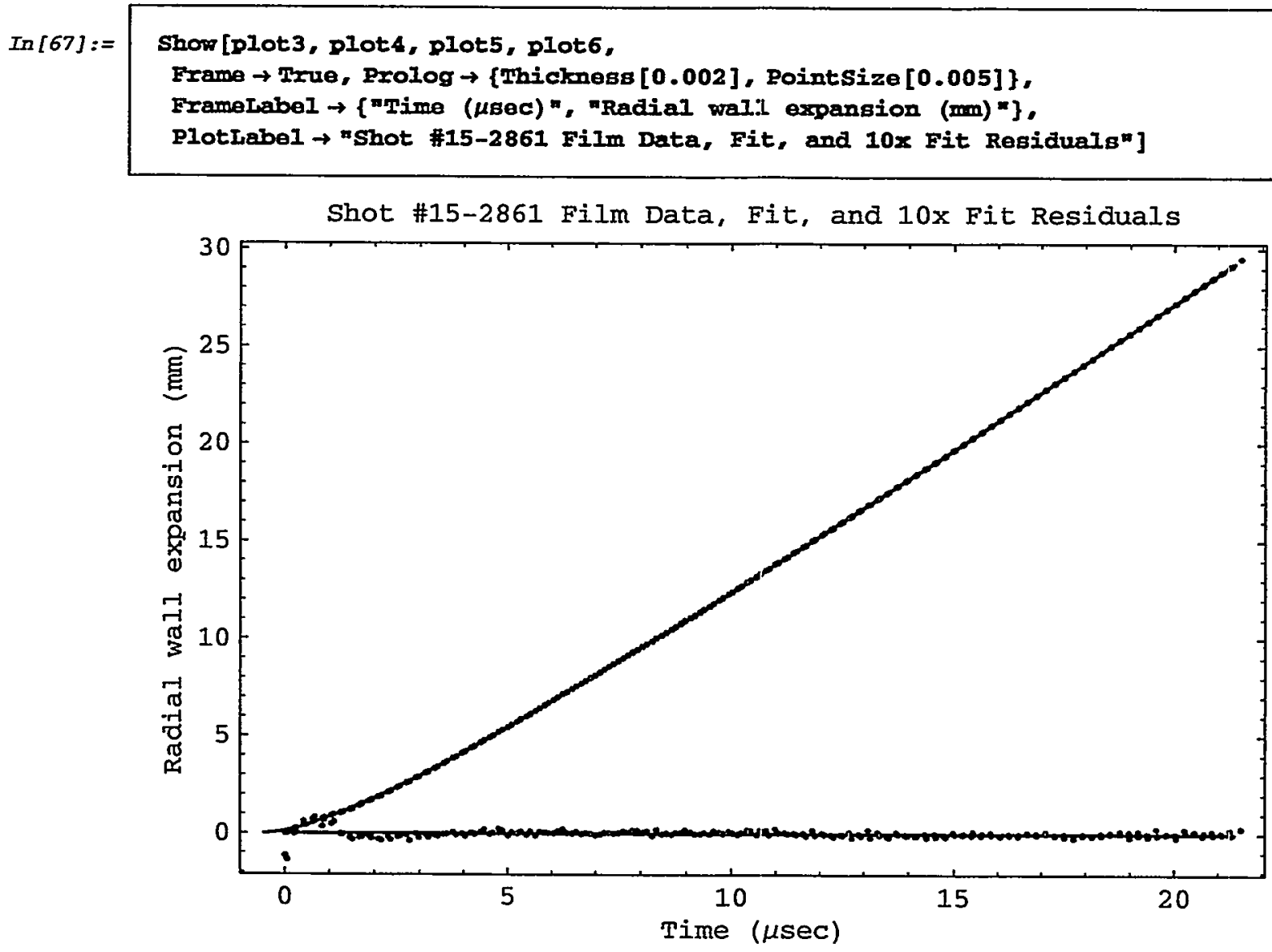

Out [67] = - Graphics - 


\section{CYLINDER TeST}

\section{n 6.3.4 Final Fit}

This is the formula used for subsequent evaluations, in which the virtual time origin is zeroed out. (The time origin is unimportant because the measures we shall compute are quoted as a function of tube expansion.)

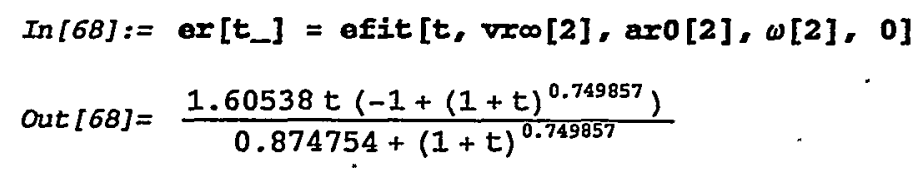

\section{- E-7. Radial Wall Velocity}

The radial wall velocity as a function of time is given by:

$\operatorname{In}[69]:=\forall x\left[t_{-}\right]=\operatorname{er}[t]$;

(The radial velocity is not the same as the material velocity of the wall, but is close to it.) The following are radial velocities at the three standard expansions. The computed times correspond to the indicated expansion in millimeters. For example, " $t 6 "$ is the time at which the wall achieved 6-mm radial expansion, and so on.

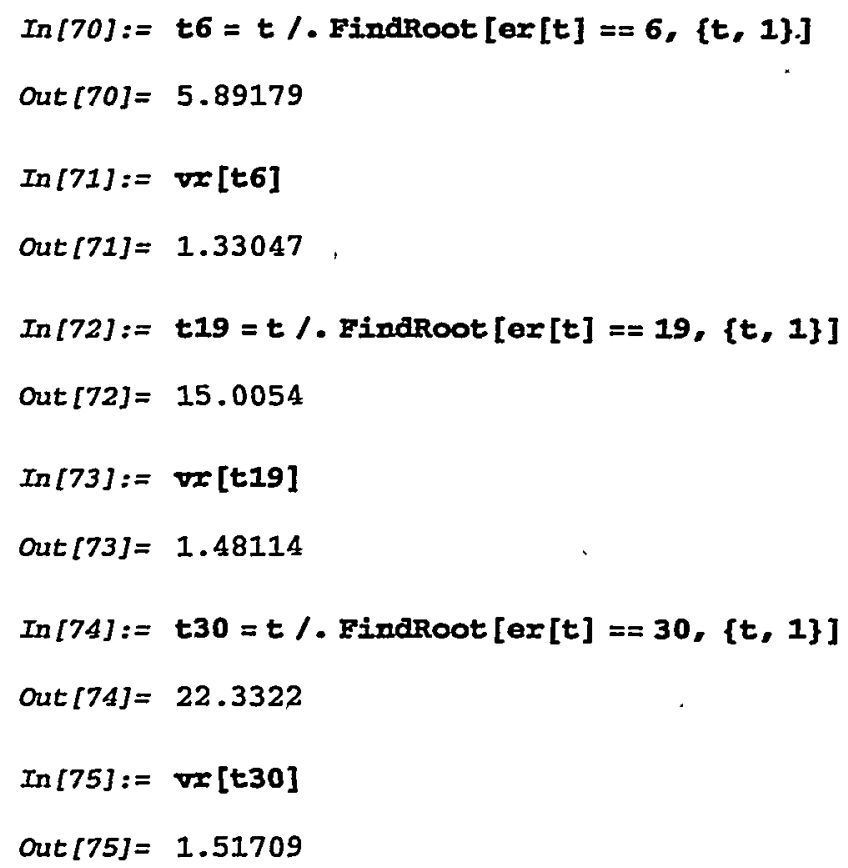

This plot shows the radial wall velocity as a parametric function of the radial wall expansion. Specify the shot number for the label: 

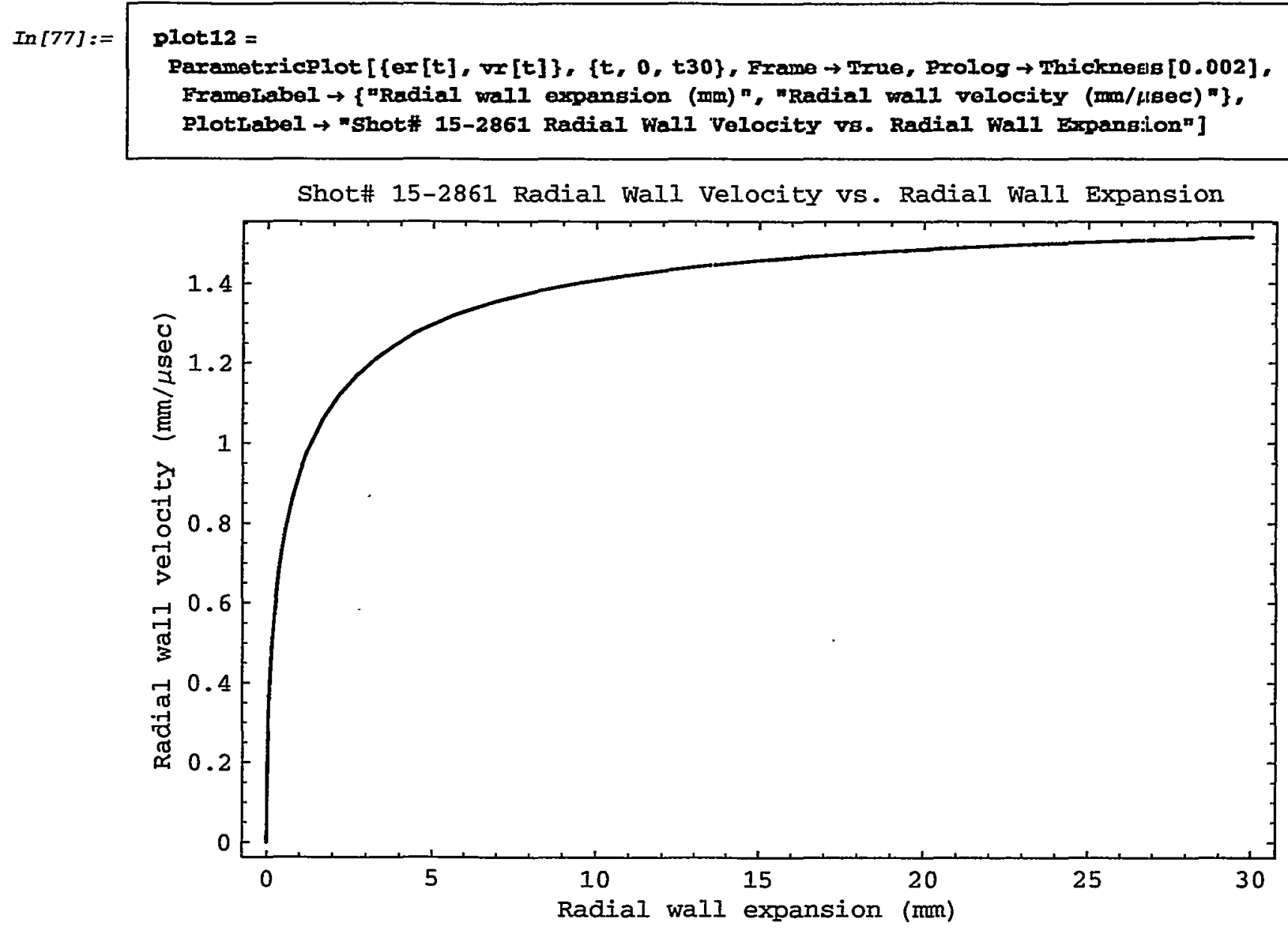

Out $[77]=$ - Graphics -

\section{E-8. Cylinder Energy}

The cylinder energy is defined as the specific kinetic energy of the wall based on the radial component of its velocity. It is not quite the same as the total specific kinetic energy of the wall, but it is close.

$\operatorname{In}[81]:=\operatorname{Egp}\left[v x_{-}\right]=\frac{v x^{2}}{2}$;

This plot shows the cylinder energy as a function of the radial wall expansion. Specify the shot number for the label: 


\begin{tabular}{|c|c|}
\hline $\operatorname{In}[82]:=$ & 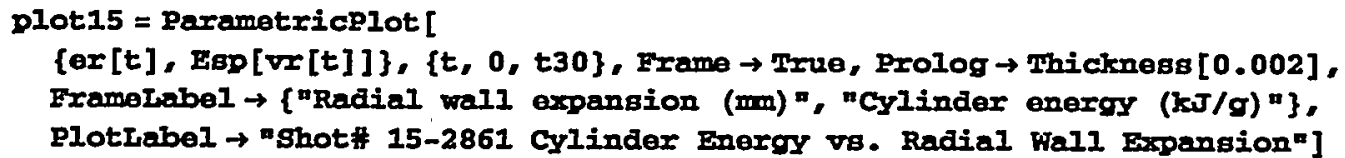 \\
\hline
\end{tabular}

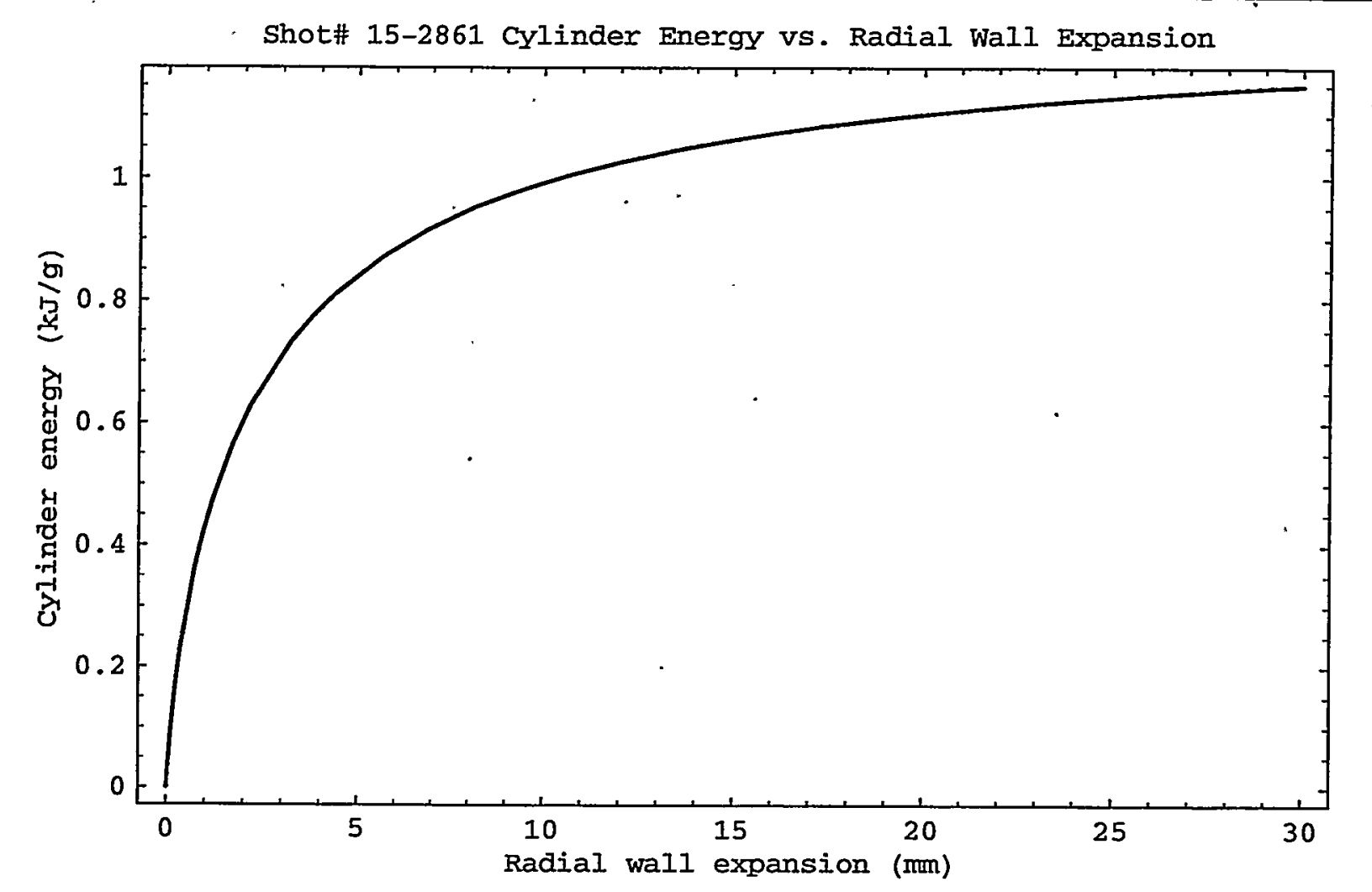

Out $[82]=$ - Graphics -

Compute the cylinder energy at the three standard radial expansions:

$\operatorname{In}[83]:=\operatorname{E6}=\operatorname{Eap}[V 2[t 6]](* \mathrm{HJ} / \mathrm{kg} *)$

Out $[83]=0.885077$

The "standard" cylinder energy is computed at 19-mm radial expansion:

$\operatorname{In}[84]:=\operatorname{E19}=\operatorname{Egp}[\operatorname{Vr}[t 19]](* 4 \mathrm{HJ} / \mathrm{kg} *)$

Out $[84]=1.0969$

$\operatorname{In}[85]:=\operatorname{E30}=\operatorname{Egp}[\mathrm{Vr}[t 30]](* \mathrm{HJ} / \mathrm{kg} *)$

out $[85]=1.15079$

The cylinder energy may also be extrapolated to infinite expansion:

$\operatorname{In}[86]:=E_{\infty}=\operatorname{Esp}[\operatorname{vrc}[2]]$ (* ijJ/kg *)

$\operatorname{Out}[86]=1.28863$ 


\section{- E-9. Gurney Energy}

The Gurney equation for cylindrical geometry:

$\operatorname{In}[90]:=G\left[V x_{-}\right]=\frac{v x^{2}}{2}\left(\frac{1}{2}+\frac{\rho 0 v\left(\left(\frac{\pi 0}{x 0}\right)^{2}-1\right)}{\rho 0}\right)$

Out $[90]=1.28583 \mathrm{vx}^{2}$

This plot shows the Gurney energy as a function of the radial wall expansion. Specify the shot number for the label:

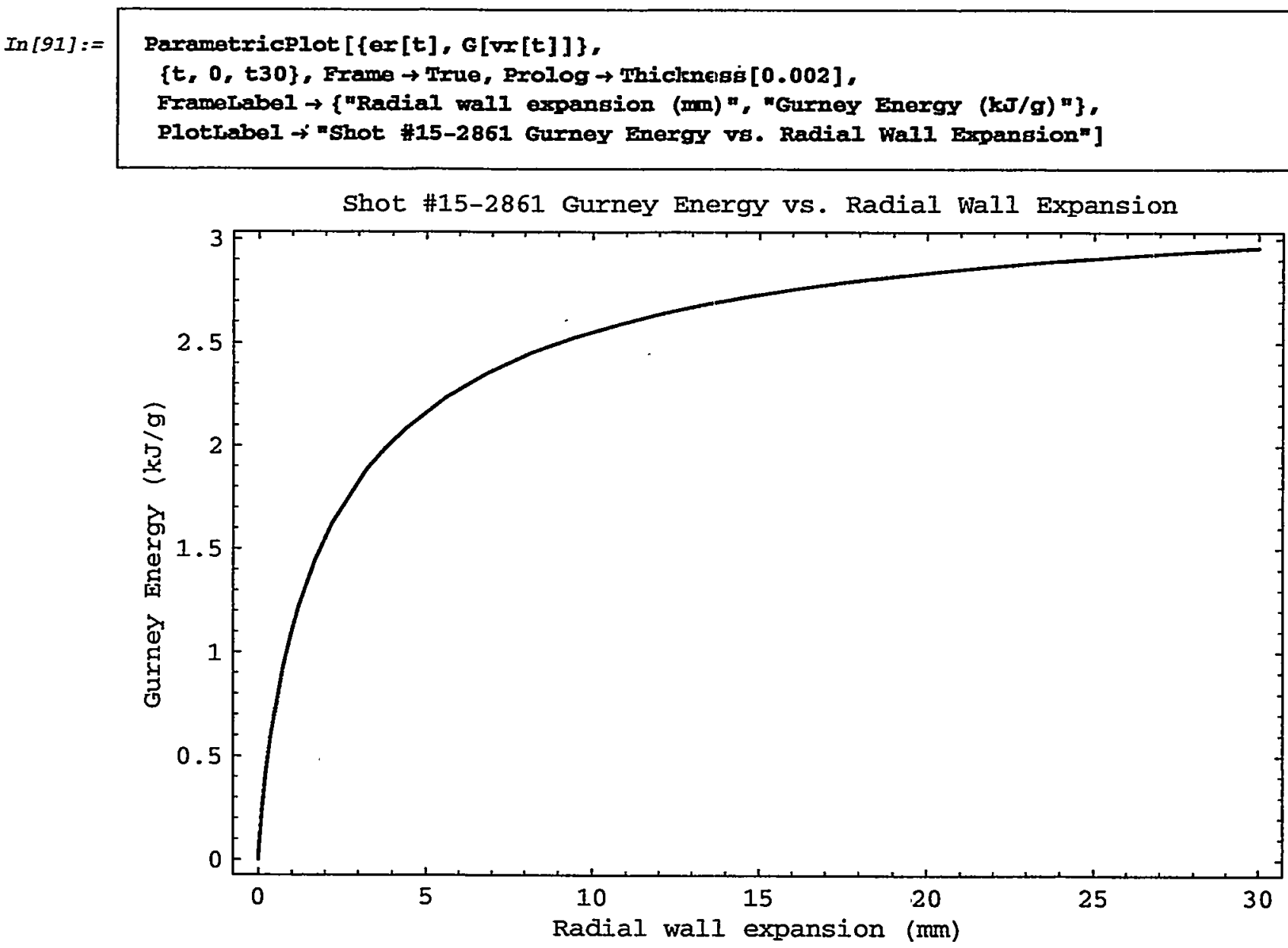

out $[91]=-$ Graphics -

Compute the Gurney energy at the three standard radial expansions:

$\operatorname{In}[92]:=\mathrm{G} 6=\mathrm{G}[\mathrm{Vx}[\mathrm{t} 6]](* \mathrm{MJ} / \mathrm{kg} *)$

out $[92]=2.27611$

The "standard" Gurney energy is computed at 19-mm radial expansion: 
$\operatorname{In}[93]:=G 19=G[\operatorname{Vr}[t 19]](* \mathrm{HJ} / \mathrm{kg} *)^{\prime}$

out $[93]=2.82083$

The "asymptotic" Gurney energy, evaluated at the asymptotic expansion velocity:

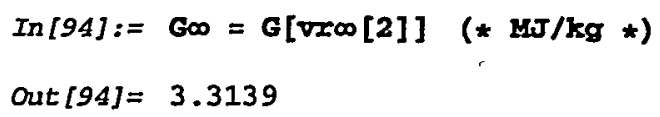

\section{E-10. Axial Velocity}

Specify the pin data in $(t, z)$ pairs, with $t$ in microseconds and $z$ in millimeters:

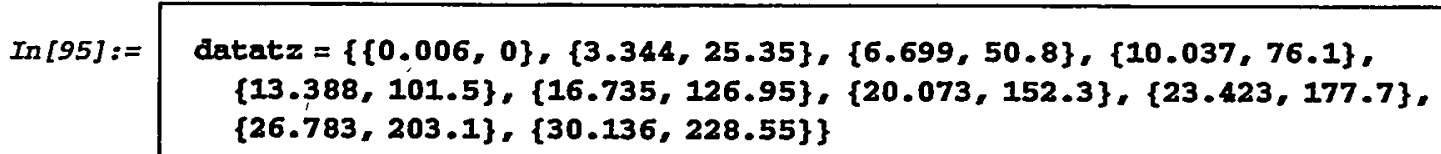

Out $[95]=\{\{0.006,0\},\{3.344,25.35\},\{6.699,50.8\},\{10.037,76.1\},\{13.388,101.5\}$, $\{16.735,126.95\},\{20.073,152.3\},\{23.423,177.7\},\{26.783,203.1\},\{30.136,228.55\}\}$

This command performs a linear fit to the data. If there are any bad pins, eliminate them from the fit using the Drop command):

$\operatorname{In}[97]:=z\left[t \_\right]=\operatorname{Fit}[$ datatz, $\{1, t\}, t]$

Out $[97]=-0.0246778+7.58576 t$

The maximum pin time is:

In $[98]:=\operatorname{tmoxpins}=\operatorname{datatz}[$ [Length $[$ datatz $] \rrbracket[1]$

Out $[98]=30.136$

These commands compute the $10 x$ fit residuals :

$\operatorname{In}[99]:=\operatorname{En} 10 x \operatorname{ReB} 3\left[w_{-}\right]:=\{w[1], 10(w[2]-z[w[1]])\}$

$\operatorname{In}[100]:=\operatorname{data10\times Res}[3]=\operatorname{Map}[\operatorname{fa} 10 \times R e B 3, \operatorname{datatz}]$;

This plot shows the $t-z$ pin data, the linear fit, and the $10 x$ fit residuals. Specify the shot number for the label: 


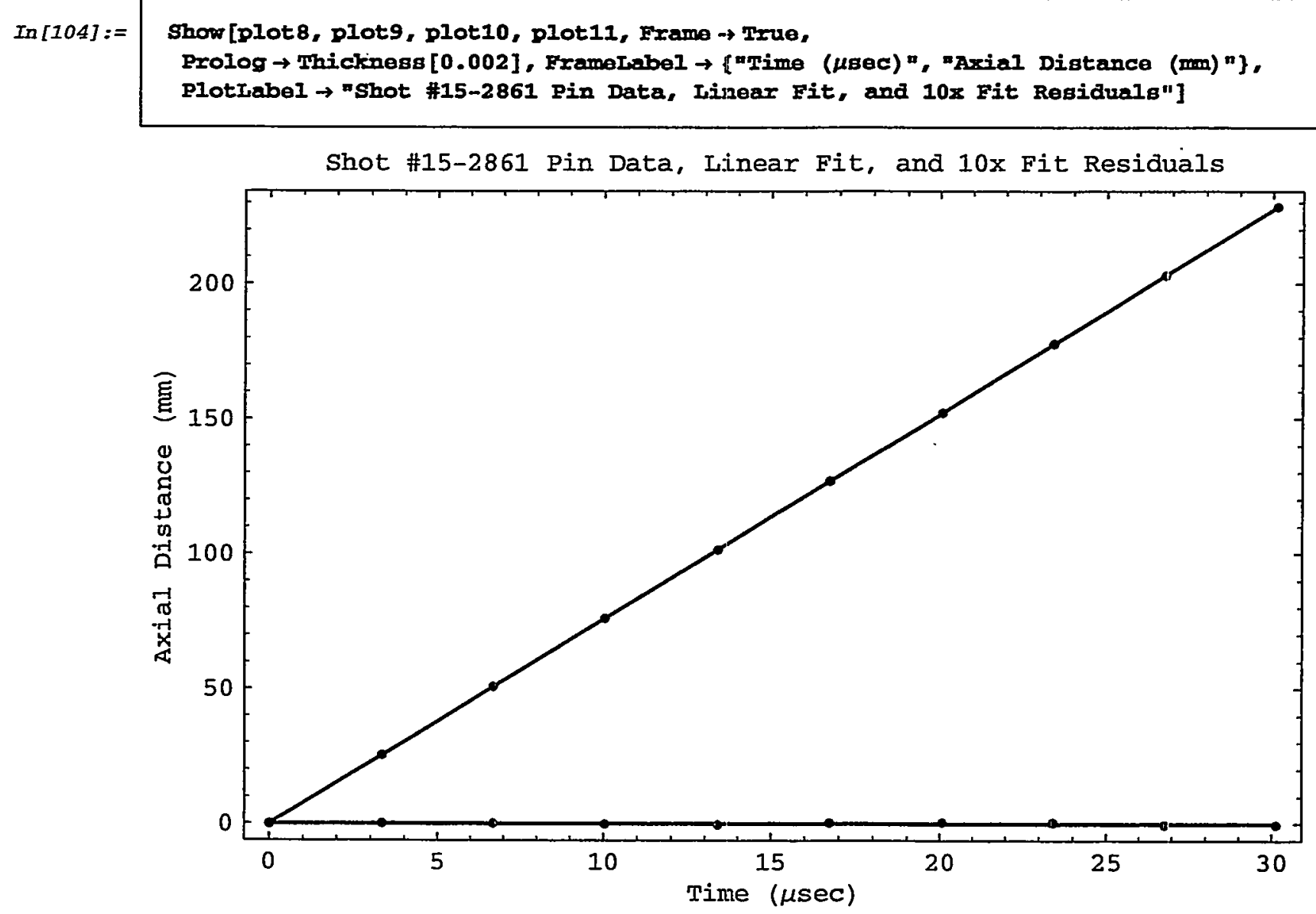

Out $[104]=-$ Graphics -

The detonation velocity is the slope of the above plot:

In $[105]:=D 0=$ Coefficient $[z[t], t]$

out $[105]=7.58576$

Perform a linear regression analysis:

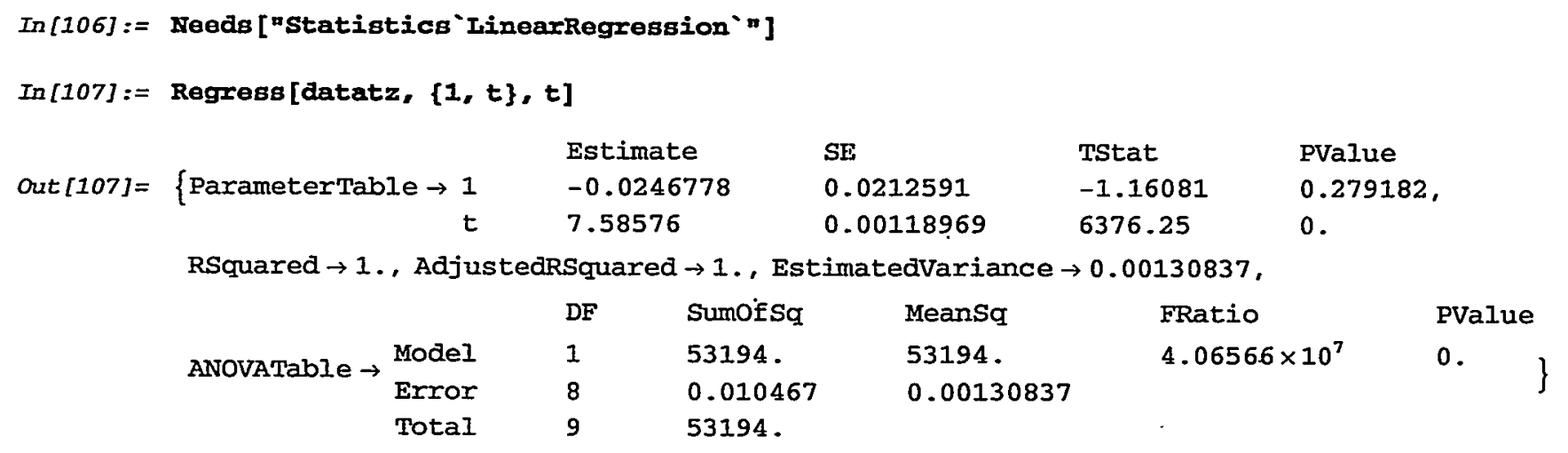

